\title{
Research Paper \\ Developing a model of effective parent-child interaction for preschool children (4 to 6 age): A qualitative study
}

\begin{abstract}
Citation: Bahrami A, Fatehizade M, Abedi A, Dayarian M.M. Developing a model of effective parent-child interaction for preschool children (4 to 6 age): A qualitative study. J of Psychological Science. 2021; 20(103): 1213-1233.
\end{abstract}

Atefeh Bahrami ${ }^{1}$, Maryam Fatehizade ${ }^{1,2}$, Ahmad Abedi ${ }^{3}, 1$

1. Department of Counseling, Khomeinishahr Branch, Islamic Azad University, Khomeinishahr, Isfahan, Iran.

2. Department of Counseling, Faculty of Education and Psychology, University of Isfahan, Isfahan, Iran.(Corresponding Author)

3. Department of Psychology and Education of Children with Special Needs, Faculty of Education and Psychology, University of Isfahan, Isfahan, Iran.

URL: https://psychologicalscience.ir/article-1-993-fa.html
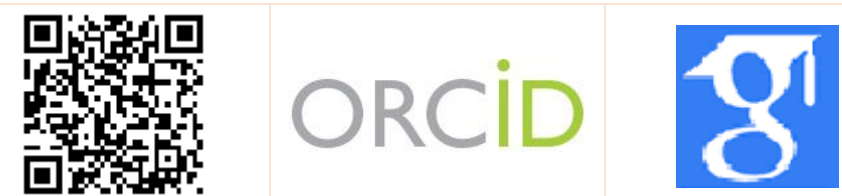

$\underline{10.52547 / J P S .20 .103 .1213}$

\section{A R T I C L E I F O A B S R A C T}

Keywords:

Parent-Child, Interactions Model, Preschool
Background: The parent-child interaction is one of the determining factor in the cognitive, social, emotional and behavioral child's development in the early years of life. However, what are the components of effective parent-child interactions model of preschool's age?

Aims: The purpose of this study is to developing a model of effective parent-child interaction for preschool children.

Methods: The present study was under qualitative research strategy based on thematic analysis method. The study's population included all resources related to parent-child interactions that was selected by purposive sampling method that after removing the inessential items, 115 sources were examined Initial data were extracted from them. Initial data were extracted from them. Data were analyzed based on Braun \& Clarke (2006) thematic analysis method and they were coded in term of parent-child interaction components.

Results: Since the primary data were rewrited and 89 basic themes were located in the first stage of coding. In the second stage 21 themes were identified. In the third stage, 8 global themes were abstracted, and thematic network was formed. Finally, the validity and reliability of model was performed using the interpretive credibility method. Therefore, the results were confirmed by expert's feedback.

Conclusion: The model of effective parent-child interaction of preschool children, has sufficient credibility. Thus, more researchers' attention to the issue of preschools' parent-child interaction, will help to develop new educational programs. It can also be a index for professionals to make parents aware the importance of parent-child interactions. Therefore, it is suggested that this model be used in the development of educational protocols based on parent-child relationships.
Received: 16 Oct 2020 Accepted: 09 Nov 2020 Available: 23 Sep 2021
* Corresponding Author: Maryam Fatehizade, Department of Counseling, Faculty of Education and Psychology, University of Isfahan, Isfahan, Iran. Department of Counseling, Khomeinishahr Branch, Islamic Azad University, Khomeinishahr, Isfahan, Iran.

E-mail: M.fatehizade@edu.ui.ac.ir

Tel: (+98) 9131004925

2476-5740/ (C) 2021 The Authors. This is an open access article under the CC BY-NC-ND license

(https://creativecommons.org/licenses/by-nc/4.0/). 


\section{Extended Abstract}

\section{Introduction}

Early childhood is the most important period of experiencing and interacting in child developmental processes (Black, Walker, Fernald, Anderson, DiGirolamo, and Devercelli, 2017). Some researchers emphasize issues beyond the transient stages of childhood development and believe that parent-child interactions play an important role in psychological development and the acquisition of basic skills in children (Maia, Frizzo and Lewandowski, 2020). Carnes-Holt, (2012) believes that parent-child interaction consists of a combination of unique behaviors, feelings and expectations in parents and children and represents security and love in relationships. The quality of parent-child interactions also affects the development of children's cognitive and social skills (Rhoades, Greenberg, Lanza, \& Blair, 2011; Miller, 2000).

Numerous studies have been conducted on parentchild interaction. The results of Mirzaei Kotnaei et al. (2015) showed that parents' interaction with their children is a determining factor in the type of children's behavior. The research of Shafiei, Hashemi Razini and Shahgholian (2017) indicated that educating parents about individual differences, positive interaction and conflict resolution is effective in reducing children's behavioral-emotional problems. The research of Roshan, Aghayusefi, Alipour and Rezaei (2016) showed that the treatment of parent-child interaction was effective in reducing the severity of children's behavioral problems. The results of Karimi and Dashtbozorgi (2019) showed a reduction in children's behavioral problems and improved mother-child relationship. The study by Masoumi-Zare, Etemadi and Ahmadi (2012) showed that the integrated approach of positive parenting and behavioral therapy is effective in improving motherchild relationship in the dimensions of conflict and dependence. The results of Tahmasebi and Khosropour (2019) showed that improving parentchild interactions is effective for social skills and cognitive regulation of children's emotion. According to Aslani, Varasteh and Amanollahi (2016), positive parenting program training affects conflict, closeness, dependence and positive relationship. Mija, Chen and Pin (2014) showed that parent-child relationship is an effective factor in the development of integrated personality in children. Research by Bussing, Nelson and Kurtz (2016); Bjorseth and Wichstrøm (2016); Damodaran (2013); Herschell, Scudder, Schaffner, and Slagel, (2017) indicated that optimal interactions are effective in reducing children's behavioral problems, mental health, and improving the parentchild relationship. Zhang (2011) and O'Connor (2006) also argued that children who have a positive relationship with their parents have a positive relationship with their preschool teachers either.

Since the emphasis on the role of parents is at the forefront of the treatment of psychological and psychiatric problems in children and adolescents (Kimber et al., 2019), parenting models to prevent children from developing behavioral and emotional disorders are of particular importance (Sanders, 2003); because it increases the self-sufficiency and self-efficacy of parents in interacting with children (Talei, Tahmassian and Vafaie, 2011).

Given this issue and few studies in the field of parentchild interaction models, it seems necessary to use a qualitative method and in-depth analysis to address factors related to parent-child interaction models. According to the investigations, no research has been conducted in Iran on the development of parent-child interaction models in preschool age; therefore, the purpose of this study is to develop a model of effective parent-child interaction for preschool children (4 to 6 years old) and the model validation.

\section{Method}

The present study was conducted using a qualitative approach and thematic analysis method. The research community and background included all written sources on parent-child interactions. Purposeful sampling was performed until saturation. In this study, written sources were examined by library method and by searching in all available Internet websites. Data coding was performed based on Braun and Clarke (2006) in a three-step method (basic themes, organizing themes and comprehensive themes). In thematic analysis, at each stage, a higher level of abstraction is obtained (Attride-Stirling, 2001). The reason for choosing the qualitative 
analysis method was that it is a process for analyzing textual data that converts scattered data into rich and detailed information (Braun et al., 2006). The data collection tool in this study was document mining in theoretical texts. The data were saturated by examining 115 written sources. The scope of the research in terms of time includes theoretical texts and studies that have been done from 1975 to 2020 .

\section{Results}

In this study, 102 English sources from 1975 to 2020 were examined. Also, there were 13 domestic studies from 2005 to 2017. In the first stage, 89 basic themes, in the second stage, 21 organizing themes and in the third stage, 8 comprehensive themes were identified and formed the themes template.

Eight comprehensive themes were obtained, each of which includes organizing and basic components. The comprehensive themes and areas covered are as follows:
1) Emotion management model in the family, which consists of two organizing themes and ten basic themes. 2) Supportive and securing behaviors model which has three organizing themes and ten basic themes. 3) Flexible environmental structure model in the family, which has two organizing themes and five basic themes. 4) Positive communication model in the family also includes two organizing themes and six basic themes. 5) Applying behavior change and correction model that has four organizing themes and seventeen basic themes. 6) Realizing child developmental dimensions model, which consists of three organizing themes and twelve basic themes. 7) Positive parenting model that has three organizing themes and two basic themes. 8) Resilience model in the family from which two organizing themes and eight basic themes were extracted. After forming the theme template, the parent-child interaction pattern was developed, which is shown in Figure 1.

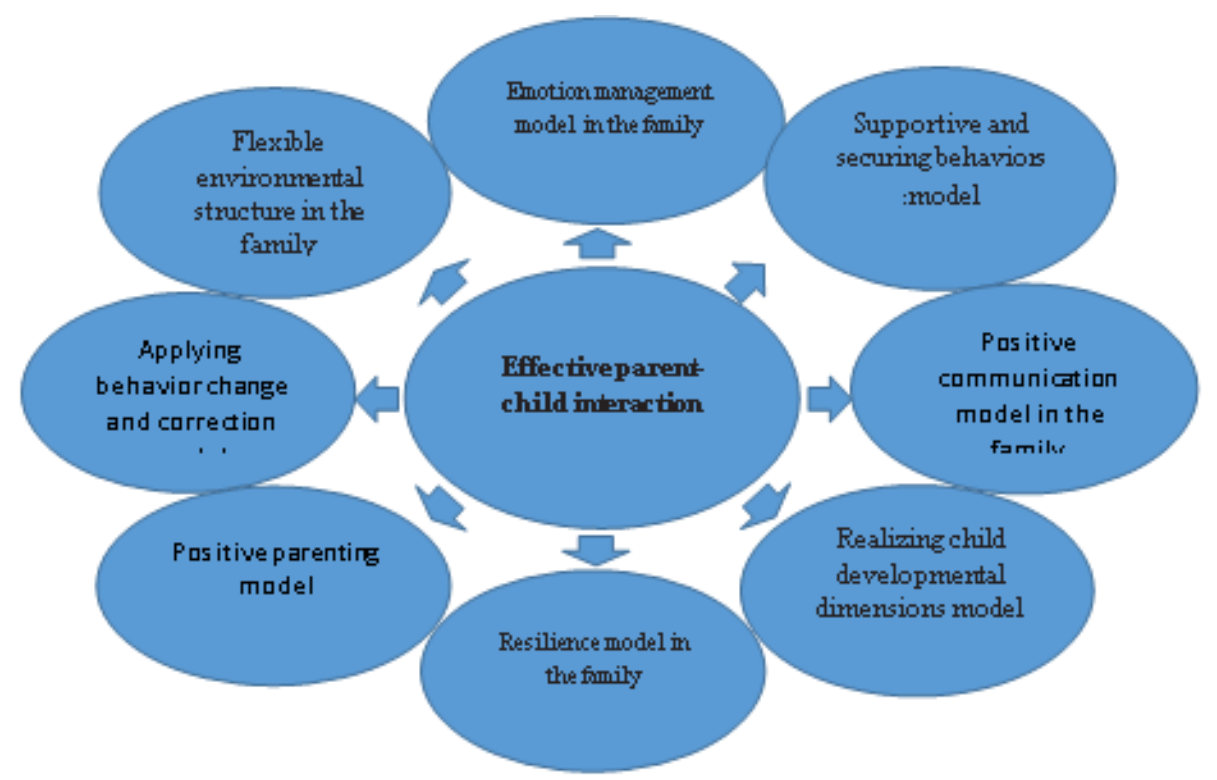

Fig. 1. Effective parent-child interaction model for preschool children Table 1.

\section{Model validation}

Researchers' self-appraisal method and inter-rater reliability were used to validate the coding. It was then given to three experts to confirm the findings. According to King and Horrocks (2010), the use of independent coders and expert panels is a common process for evaluating and controlling the quality of content analysis (quoted by Abedi Jafari et al., 2011; King, Horrocks and Brooks, 2018).

\section{Conclusion}

The final components related to effective parent-child interactions for preschool children (4 to 6 years old) include the following 8 themes:

Emotion management model in the family: Since parents play an effective role in children's guidance and emotions expressions (Comer et al., 2012; Labi et al., 2019), parents who manage their stress well, may use strategies that increase positive responsiveness to 


\section{Monthly Journal of Psychological Science}

Vol. 20, No. 103, Autumn(October) 2021

their children (Stewart and Emslie, 2020; Maliken and Katz, 2013).

Supportive and securing behaviors model: Supportive behaviors lead to the child's cognitive (Landry, Smith, Miller, \& Swank, 1997), social development (Donovan, Stoyles and Berry 2010), and create the opportunity for choice and self-efficacy (Pajares and Schunk 2001; Stephen, 2009; Zhang, 2011).

Flexible environmental structure in the family: Since the family is the first founder of personality in the child (Mei-Ju, Chen-Hsin, and Pin-Chen, 2014), behavioral disorders occur in families with unhealthy structures (Ahadi, Hejazi, and Foumani, 2014; Yaacob and Su, 2010). Stright, Neitzel, Sears, \& Hoke-Sinex (2001); McCabe, Yeh, Lou, Argote, and Liang (2010); Maher, Marcynyszyn, Corwin, and Hodnett (2011) argue that providing an informal learning environment in the family stimulates the child's interest in problem-solving, acquiring skills, and purposeful behavior, and it is a commitment to children's happiness and well-being.

Positive communication model in the family: Interactions are the first base of cognition in individuals (Issa Nejad, Ghasemi and Khandan, 2017); children in positive interactions with parents and in the family environment, can learn and practice new social and cognitive skills to help them connect with others (Myers and Pianta, 2008; Zhang, 2011; Romanowicz, 2019).

Applying behavior change and correction model: Changing parental behaviors toward positive behaviors (Bagner and Eyberg, 2007) provide adaptive models for children (Myers et al., 2008). Appropriate parental approach leads to behavior management (Schuman et al., 2013) and dysfunctional parenting styles and inappropriate interactions will lead to communication problems and disorders such as anxiety, behavioral problems, and psychological trauma. According to Damodaran (2013), and Labi et al. (2019) the aim of improving the quality of parent-child interaction is to reduce behavioral problems and strengthen socially appropriate behaviors.

Realizing child developmental dimensions model: Early childhood is a period of rapid physical development and the child acquires a set of skills and abilities (Al Nofal and Schwenk, 2013). The type of parent-child relationship affects the child's developmental dimensions, including cognition, language skills, social and emotional competencies (Jeon, Peterson, and DeCoster, 2013; GoLinkoff, Can, Soderstrom, and Hirsh-Pasek, 2015; Pempek and Lauricella, 2017).

Positive parenting model: Teaching positive parenting practices to parents and (Labi et al., 2019), is centered on enhancing parents' attention to the child's positive behaviors, enhancing praise and admiration (McCabe et al., 2010). Parents who use positive parenting practices, set less strict rules and have more positive behaviors toward their children (Bondy and Mash, 1999; Labi et al., 2019).

Resilience model in the family: Improving the quality of parent-child interactions, is effective in preventing relationship tensions (Damodaran, 2013) and improving the symptoms of disorders such as confrontational disobedience in children (ChronisTuscano et al., 2016) because parenting stress and psychological disorders such as depression are more common in parents of children with behavioral problems (Mazursky-Horowitz et al., 2015).

There are several similarities between the components in this model with the results of previous research. However, despite these similarities, none of the previous studies has provided a comprehensive process of all components related to parent-child interactions, and in this study, a relatively comprehensive model with sufficient validity has been developed in this field.

\section{Ethical Considerations}

Compliance with ethical guidelines:

from the doctoral dissertation of the first author in the field of counselling at Khomeini Shahr Islamic Azad University with the date of approval 7 July 2019; the required permissions for conducting the research have been approved and issued by Khomeini Shahr University.

Funding: This research is in the form of a doctoral dissertation without financial support.

Authors' contribution: The first author is the main researcher of the research. The second and third authors are the supervisors and the fourth author is the advisor.

Conflict of interest: The authors in this study do not declare any conflict of interest.

Acknowledgments: We hereby thank and appreciate the supervisors and advisor. 
تدوين الكوى تعامل مؤثر والد - كودكى براى كود كان ييش از دبستان (ع تا 7 سال): يكى مطالعه كيفى

\section{عاطفه بهر امى'، مريم فاتحىزاده" او'، احمد عابدى'، محمد مسعود دياريان'}

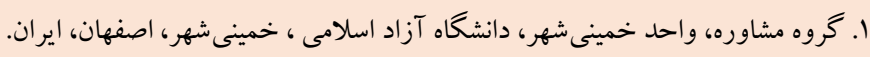

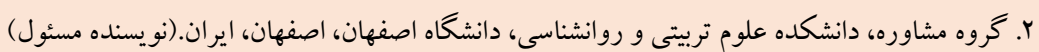

r. گروه روانشناسى و آموزش كود كان با نيازهاى خاص، دانشكده علوم تربيتى و روانشناسى، دانشكاه اصفهان، اصفهان، ايران.

زمينه: تعاملات والد - كود كك در سالهاى اوليه زندگى، يكى از مهم ترين عوامل تعيين كننده در رشد شناختى، اجتماعى، عاطفى و رفتارى

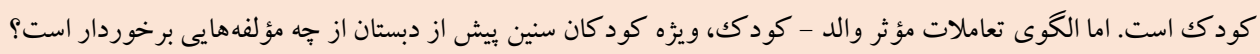
هدف: هدف از ئزوهش حاضر تدوين الكوى تعامل مؤثر والد - كودك ويثه كود كان بيش از دبستان است. روش: مطالعه حاضر بر اساس رويكرد كيفى و روش تحليل تماتيك انجام شد. جامعه مورد مطالعه شامل كليه منابع نوشتارى مرتبط با

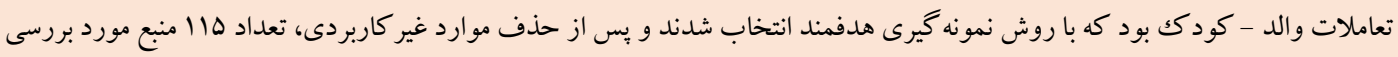

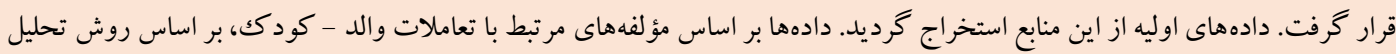

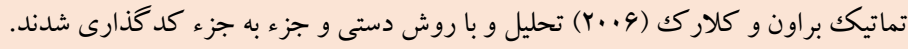

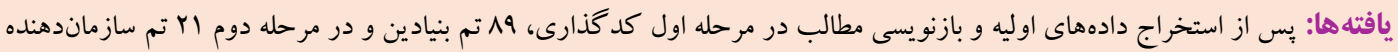

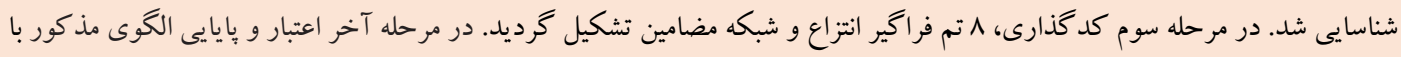

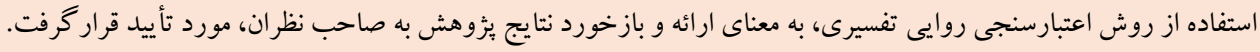

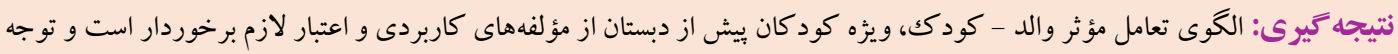

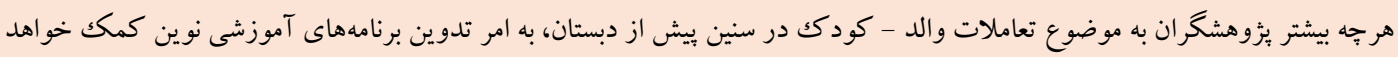

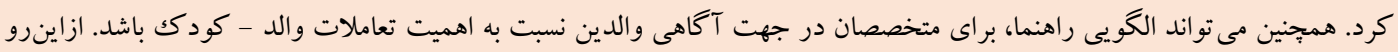
ييشنهاد مىشود اين الكو در تدوين بروتكلهاى آموزشى مبتنى بر روابط والد - كودكك مورد استفاده كيرد.
مشخصات مقاله الكوى تعاملات والد - كودكى، يِيش از دبستان
دريافت شده: V/r •/rqه

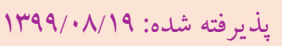

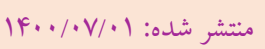

*ُ نويسنده مسئول: مريم فاتحىزاده، گروه مشاوره، دانشكده علومتربيتى و روانشناسى، دانشگاه اصفهان، اصفهان، ايران. گروه مشاوره، واحد خمينىشهر، دانشگاه آزاد اسلامى،

خمينىشهر، اصفهان، ايران. رايانامه: m.fatehizade@edu.ui.ac.ir 
اجتماعى كودكان، نتيجه ارتباط مؤثر با والدين است (مايلر، Y...Y). تعاملات كار آمد والدين و كودكان در دوران كودكى، مؤلفه يِشيشى بينى

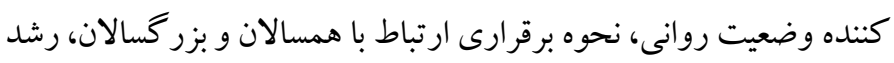

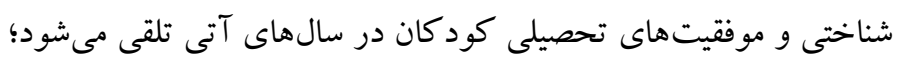

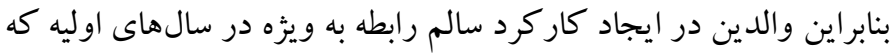

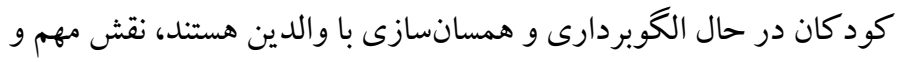

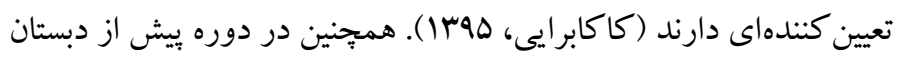

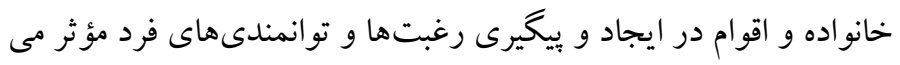

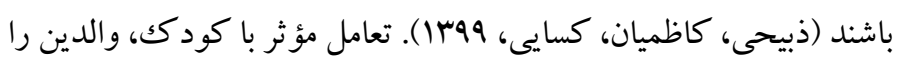
قادر مى سازد تا كود كان خود را همانطورى كه هستند بيذيرند و از تمايل به تغيير كودكان مطابق با خواستهاى خود صرفنظر نمايند. مى توان اين گونه استنباط نمود كه تعاملات والد و كودكى، يك فرد فر آيند دوسويه است و هر دو گروه والدين و فرزندان از يكديخر تأثير مى يذيرند

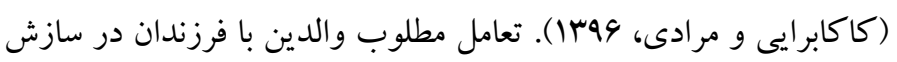
يافتكى رفتارى، اجتماعى و تحصيلى كودكان نيز نقش بسيار مهمى دارد

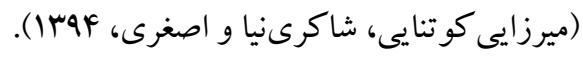
يثزوهشهاى متعددى در خصوص تعامل بين والد و كودكك انجام شده

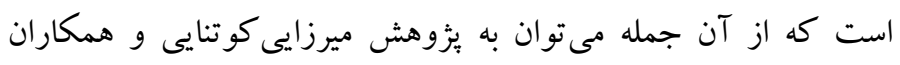
(ITAF)

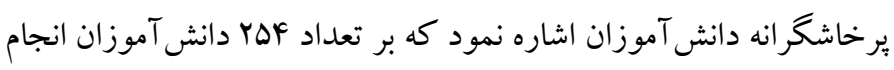

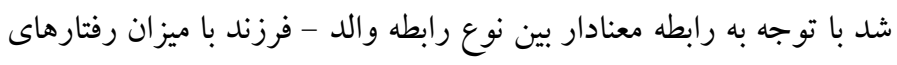

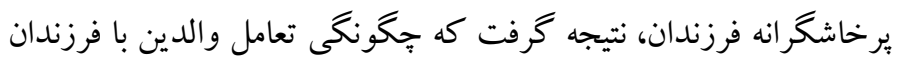

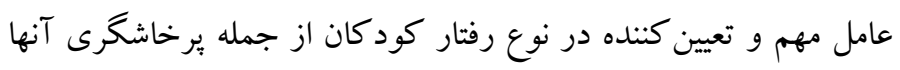

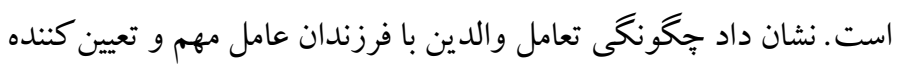

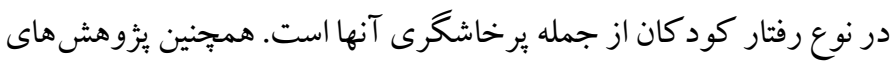

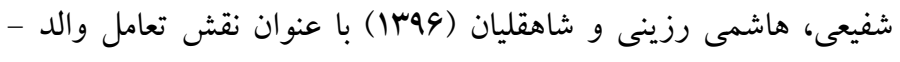
كودكى و الكوى بردازش حسى در تشخيص مشكلات درونى سازى و و

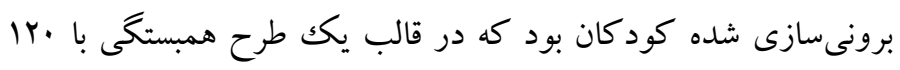

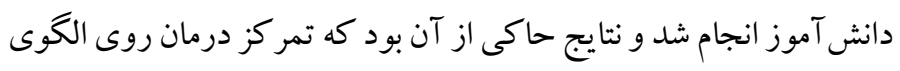

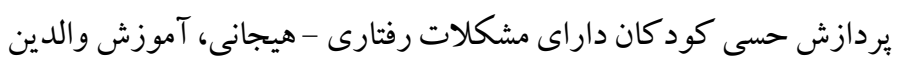

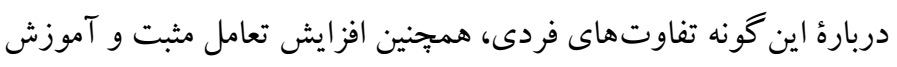
حل تعارض به والدين در كاهش مشكلات رفتارى - هيجانى كود كان مؤثر

\section{dolقo} كودكى اوليه، مهمترين دوران تجربهاندوزى و تعامل ميان فرآيندهاى

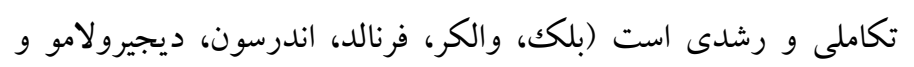

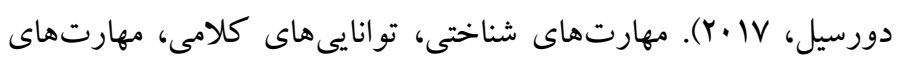
اجتماعى و حر كتى مبانى ياد گيرى هستند كه در طول دوره ييش از دبستان

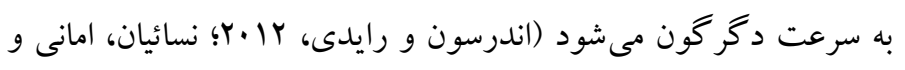

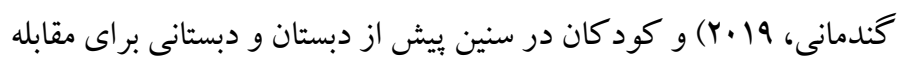

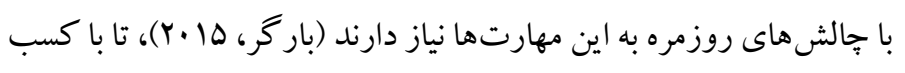

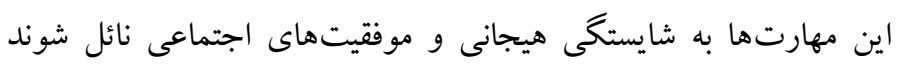

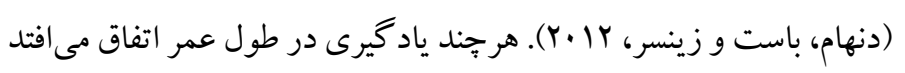

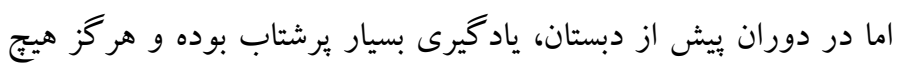

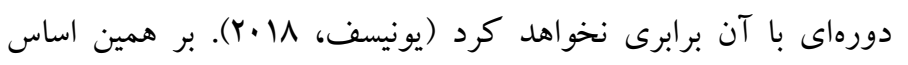

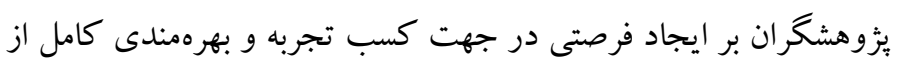

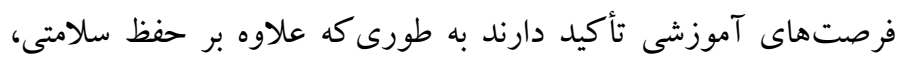
دورههاى كذراى رشدى كود كك به صورت موفقيت آميز طى شود و رشد رشد

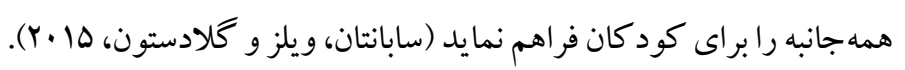

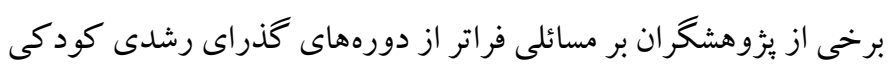

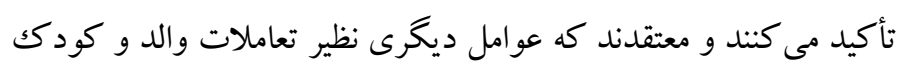

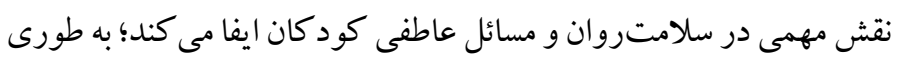

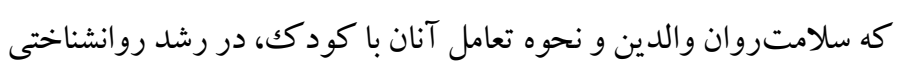
و اكتساب مهارتهاى بايه در كود كان بسيار حائز اهميت است (مايا، فريزو

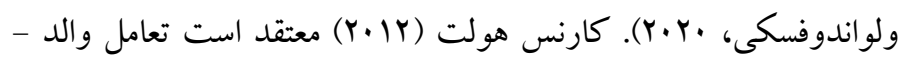

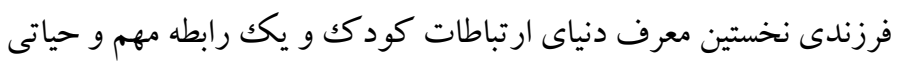
براى ايجاد امنيت و عشق است كه متشكل از تركيبى از رفتارها، احساسات

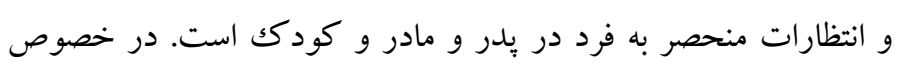

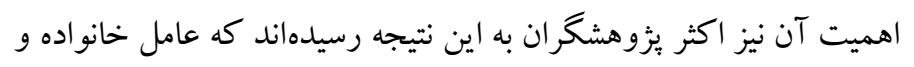

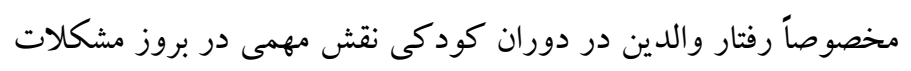

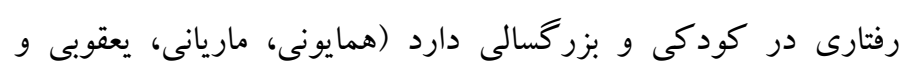

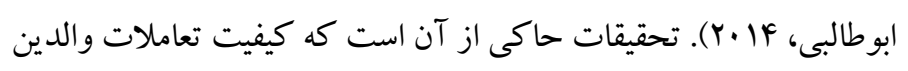

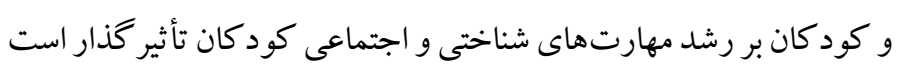

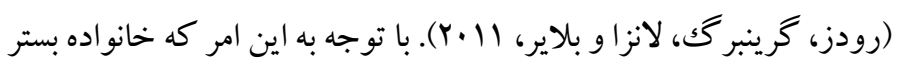
آغاز و شكل گيرى زندگى آدمى است رشد مطلوب و سلامتروانى - 


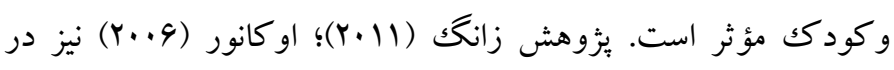
يُوهش هاى خود نشان دادند كه كود كانى كه با والدين خود روابط مثبت

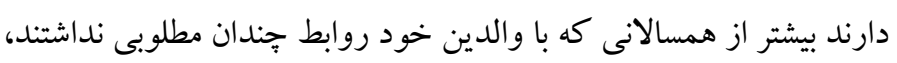
با معلمان بيش دبستانى خود رابطه مثبت برقرار مى كنند.

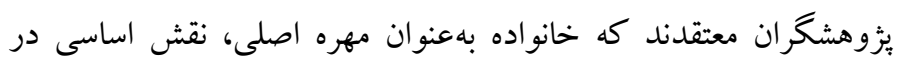

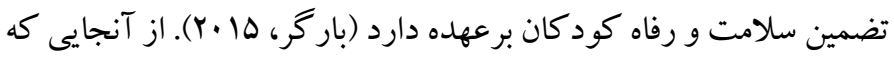
خانواده بهعنوان مركز و هسته اصلى مراقبت است، موفقيت در ايجاد

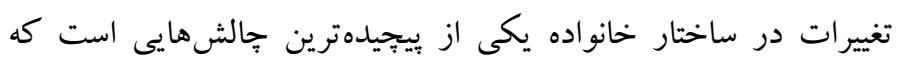

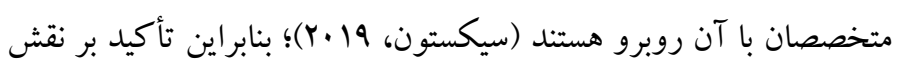

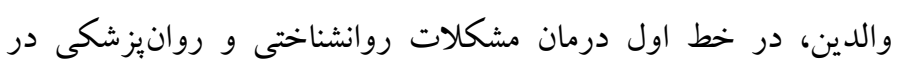

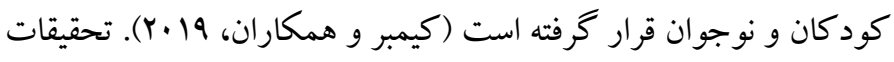
نشان داد مؤثرترين خدمات آنهايى هستند كه بر نقش خان وران أنواده تأكيد

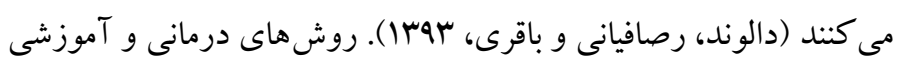

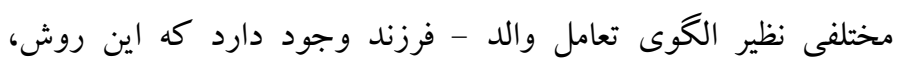
تكنيككاى رفتارى و سنتى را در جهت كاهش مشكلات روانشناختى و

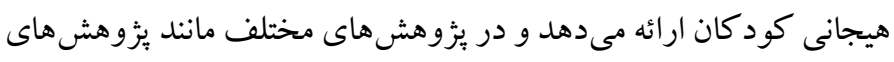

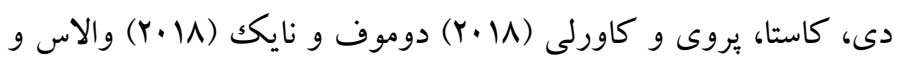

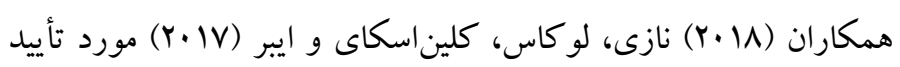

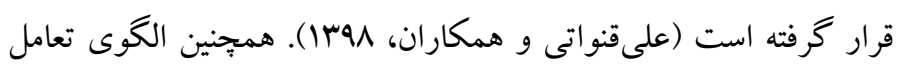

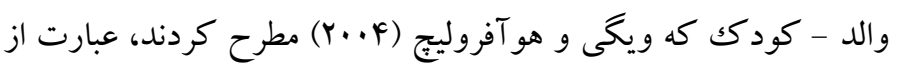

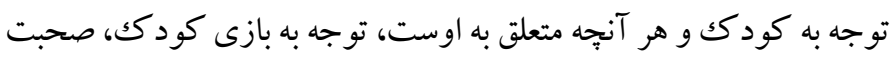

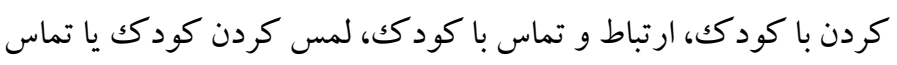

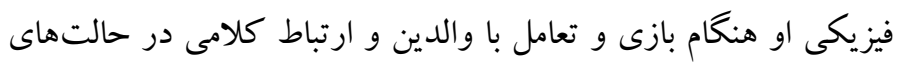

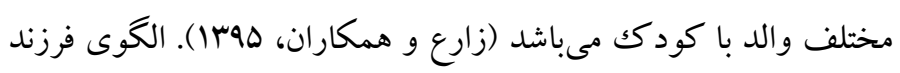

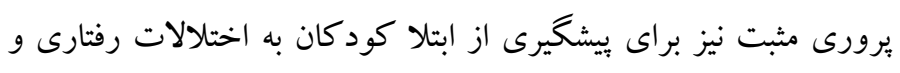

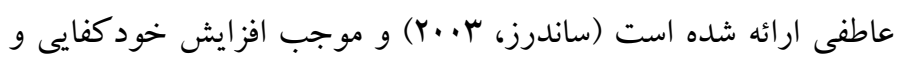

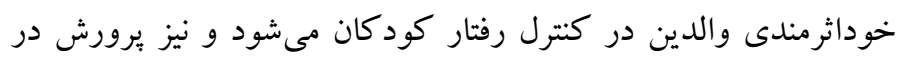

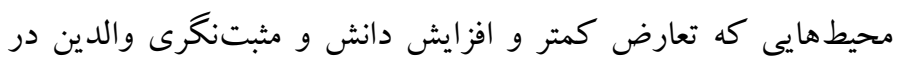
تربيت كود كان را آموزش مىدهد؛ اين الكو شامل جهار مهارت تقويت

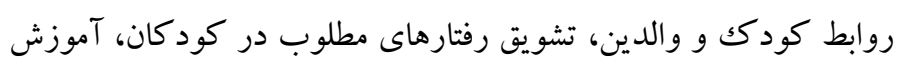

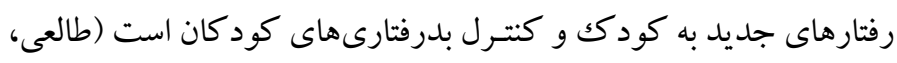
طهماسيان و وفايى، •وسا). درمان رابطه والد - فرزند براتون و لندرث

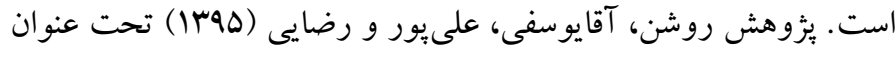

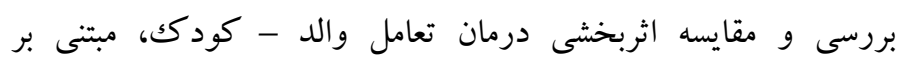

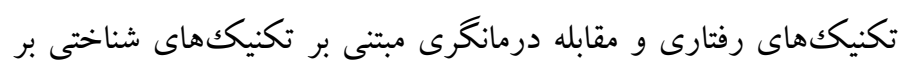
كاهش شدت مشكلات رفتارى در نمونهاى با تعداد •ه نفر از كود كان

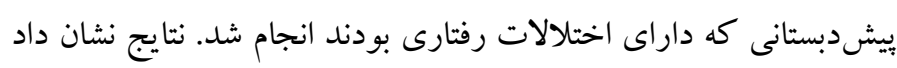

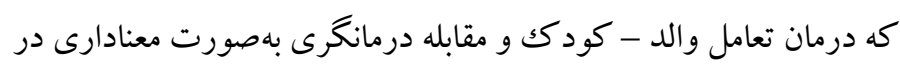
كاهش شدت مشكلات رفتارى كودكان مؤثر بود. بثوهش كريمى و

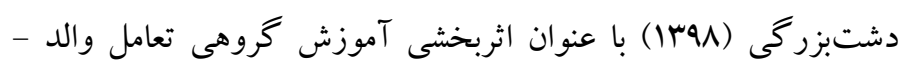

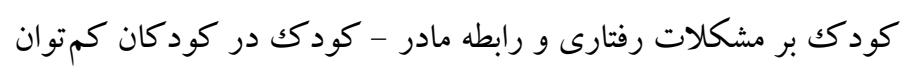

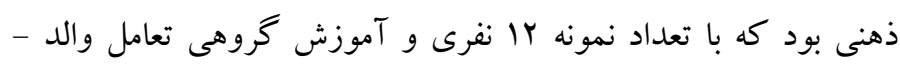
كودكى باعث كاهش مشكلات رفتارى كود كان و بهبود رابطه مادر -

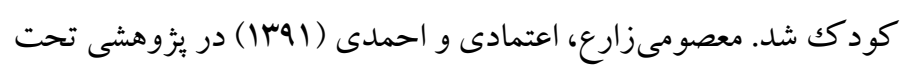
عنوان بررسى اثربخشى رويكرد تلفيقى فرزنديرورى مثبت و رفتاردرمانى به شيوه گروهى بر بهبود ارتباط مادر - كود كك با نمونه ها نفرى انسى از مادران

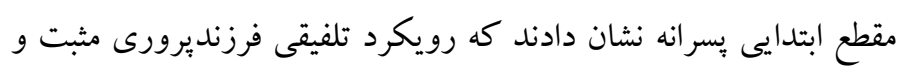

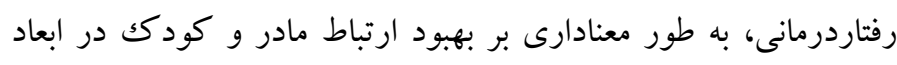
تعارض و وابستخى اثربخش است. نتايج بثزوهش طهماسبى و خسرويور (1) (1) با عنوان اثربخشى درمان مبتنى بر رابطه والد - كودك بر بر مهارت هاى اجتماعى و تنظيم شناختى هيجان كود كان زير بان آسال مبتلا به اختلال

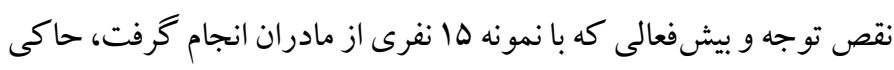

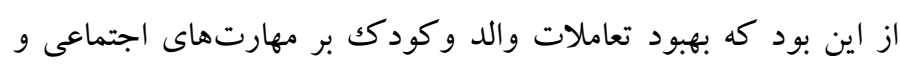
تنظيمشناختى هيجان اين كودكان اثرات مثبى دارد. همجنين اصلانى، بودي،

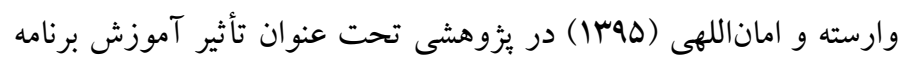

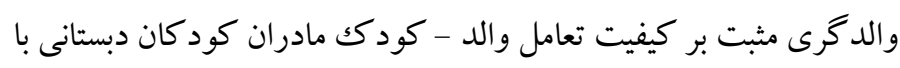

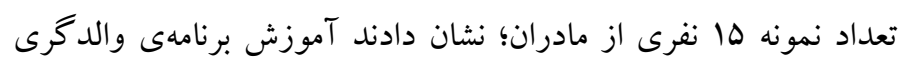

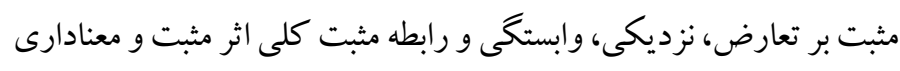

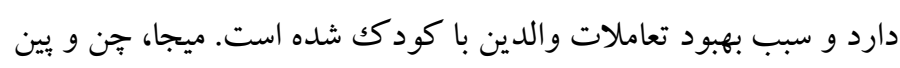
نشان دادند روابط والدين و فرزندان ازعوامل مؤثر در رشد بـ (Y.|F)

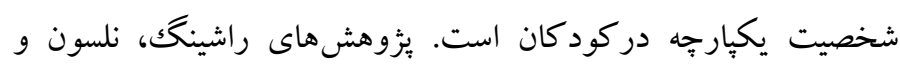

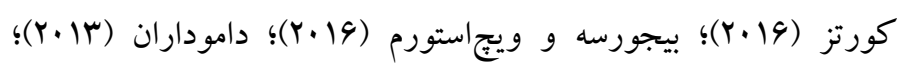

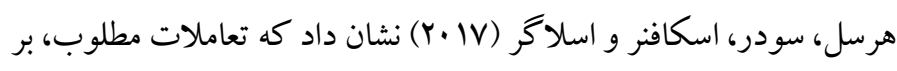
كاهش مشكلات رفتارى كود كان، سلامتروانى و بهبود رابطه والد 
و جستجو در متون قابل دسترس بود. ابتدا يزوهشگران كليه متون نظرى

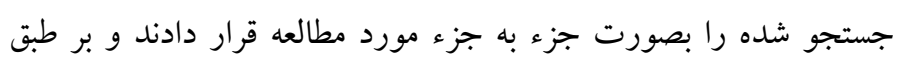

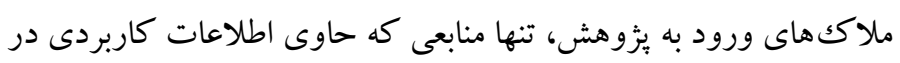

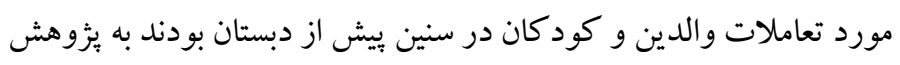

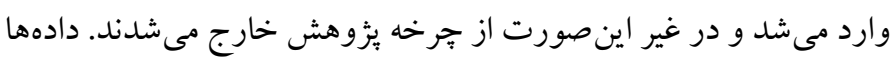

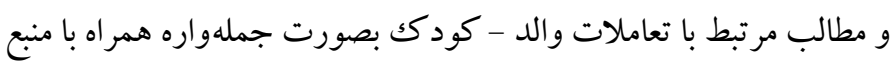

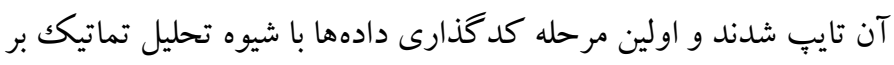

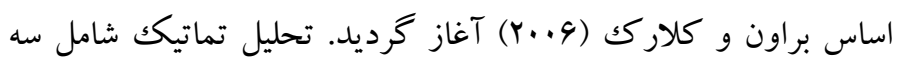

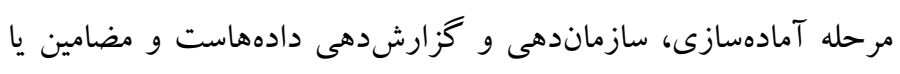
تمها مبين اطلاعات مهمى درباره دادهها و سؤالات تحقيق است و مفهوم

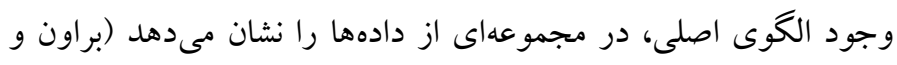

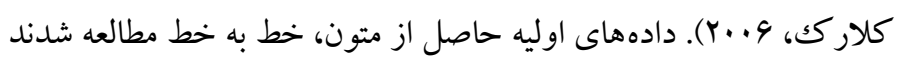
و بهصورت دستى كد گذارى و تايب شدند. مرحله اول شامل كد گذارى تمهاى بنيادين بود كه از درون دادههاى اوليه استخراج شد. در مرحله دوم

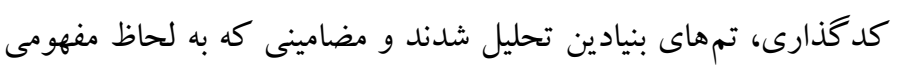

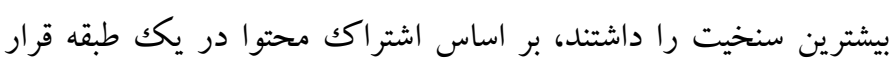

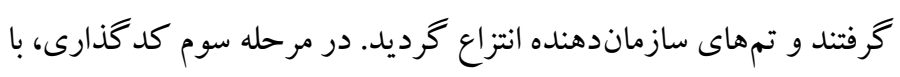

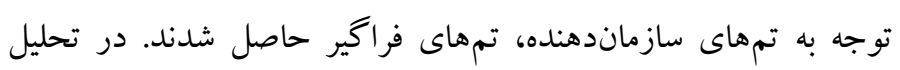
تماتيك، با وجوديكه تمامى مراحل با تحليل و تفسير همراه است، اما در تران

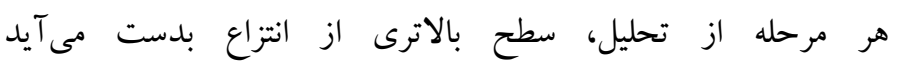

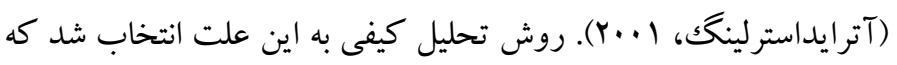

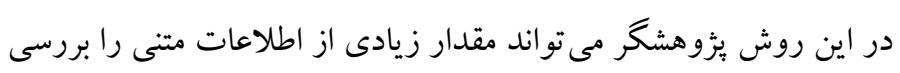

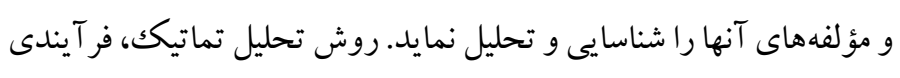

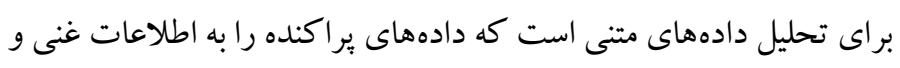

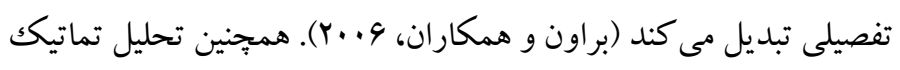
يكى از روشهايى است كه مى تواند جهت شناخت الكوهاى دادئ دادهاى

كيفى بكار رود (عابدى جعفرى، تسليمى، فقيهى و شيخزاده، •وبها).

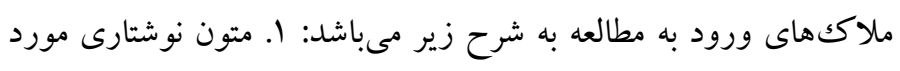

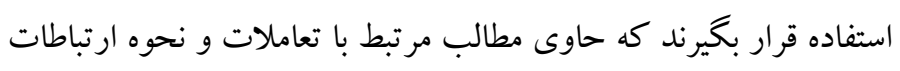

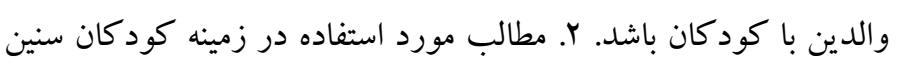

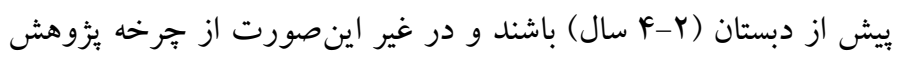
خارج مىشد.
(Y.19) نيز درواقع نوعى از درمان تبارى و خانو اده درمانى با محوريت

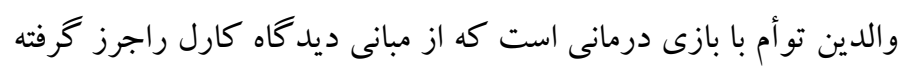

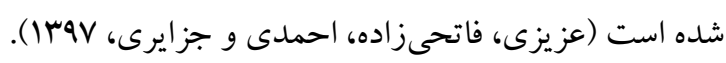

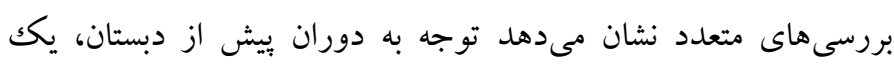

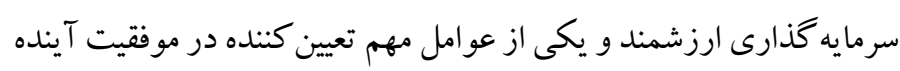

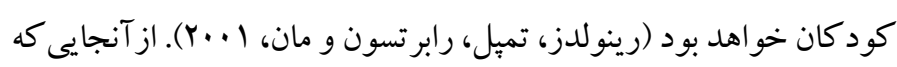
تعاملات خانو اده بيشترين تأثير را بر رشد كود كان دارد، توجه به كود كان

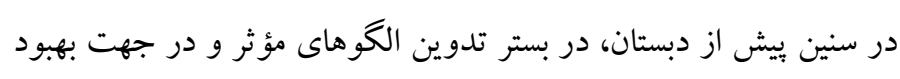
تعاملات والد - كودكك سوق بيدا كرده است. با توجه به اهميت دوران

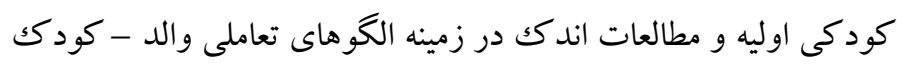
ضرورى به نظر مىرسد كه با استفاده از روش كيفى و بصورت عميق به وديه بررسى و واكاوى عو امل مر تبط با الكوهاى تعامل والد كود كك انجام گيرد.

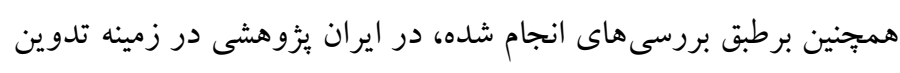

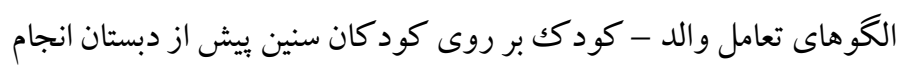
نشده است؛ لذا هدف اين بثزوهش تدوين الكوى تعامل مؤثر والد - كود كى نك

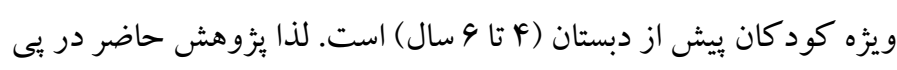

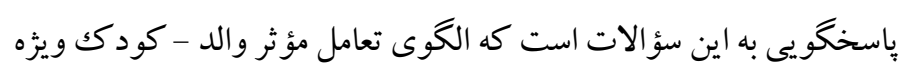

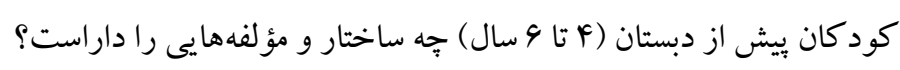
علاوه بر آن، آيا الكوى تعامل مؤثر والد - كودكك از اعتبار و روايى لازم

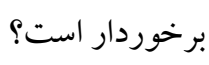

روش الف) طرح ئوهش و شركت كنند كان: يزوهش حاضر با استفاده از رويكرد كيفى و روش تحليل تماتيك انجام شد. جامعه مورد مطالعه و زمينه

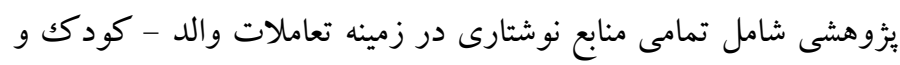

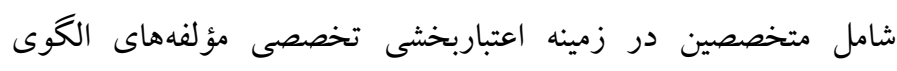

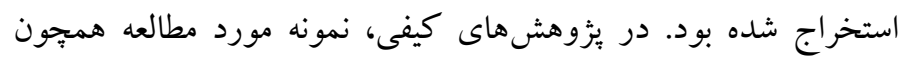

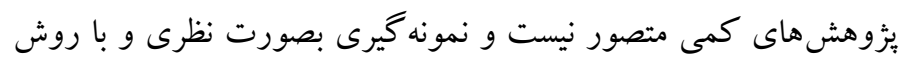

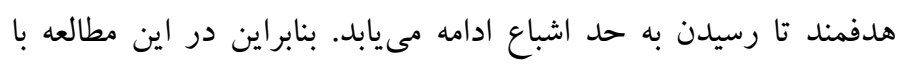

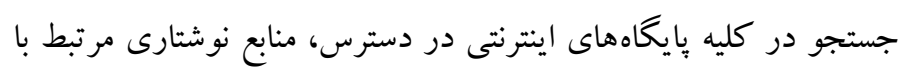

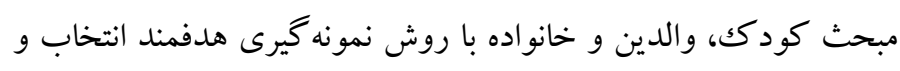

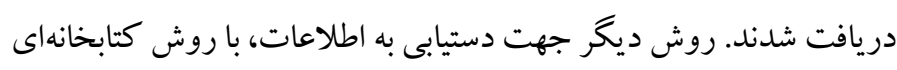




\section{يافته ها}

در اين مطالعه، تعداد هالما منبع نوشتارى مورد بهرهبردارى قرار گرفتند.

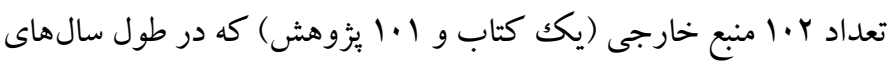

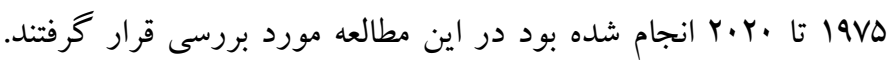
همجنين تعداد يُزوهشهاى داخلى سا مورد مى باشد كه در طى سالهاى د أس IrAF بررسىها صرف نظر شد. به منظور تحليل دادها از روش قالب مضامين

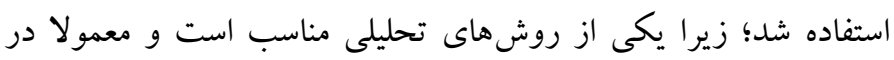

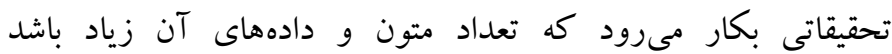
(عابدىجعفرى و همكاران، •وس1). به منظور دستيابى به باسخ سؤال اول،

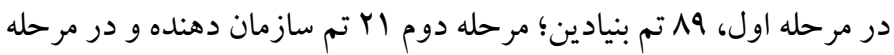

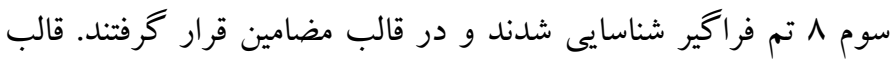
مضامين در جدول انشان داده شده است.

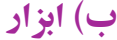
ابزار كردآورى اطلاعات در اين يُزوهش، سندكاوى، متون نظرى و

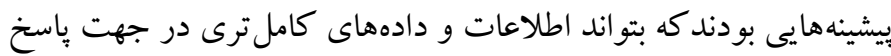

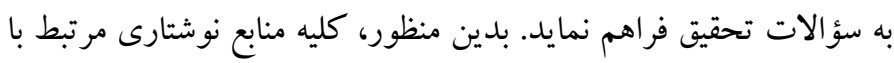

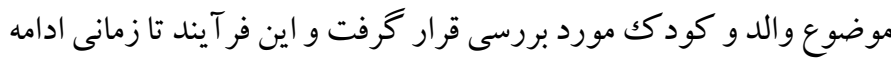

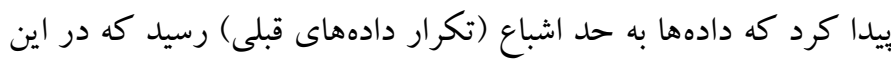

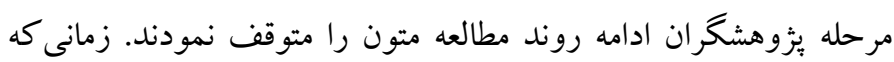

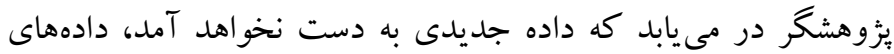

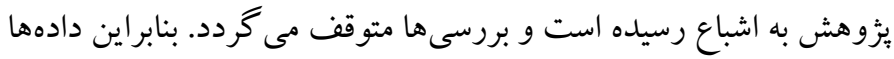

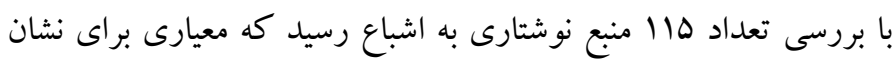

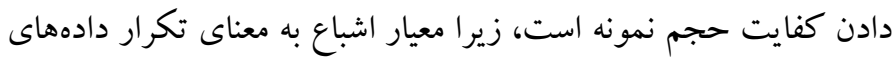
قبلى است. قلمرو تحقيق به لحاظ زمانى شامل متون نظرى و يثزوهشهايى

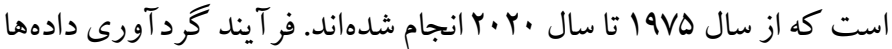

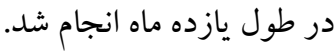

جدول ا. فر آيند تحليل قالب مضامين تعاملات مؤثر والد - كودكى

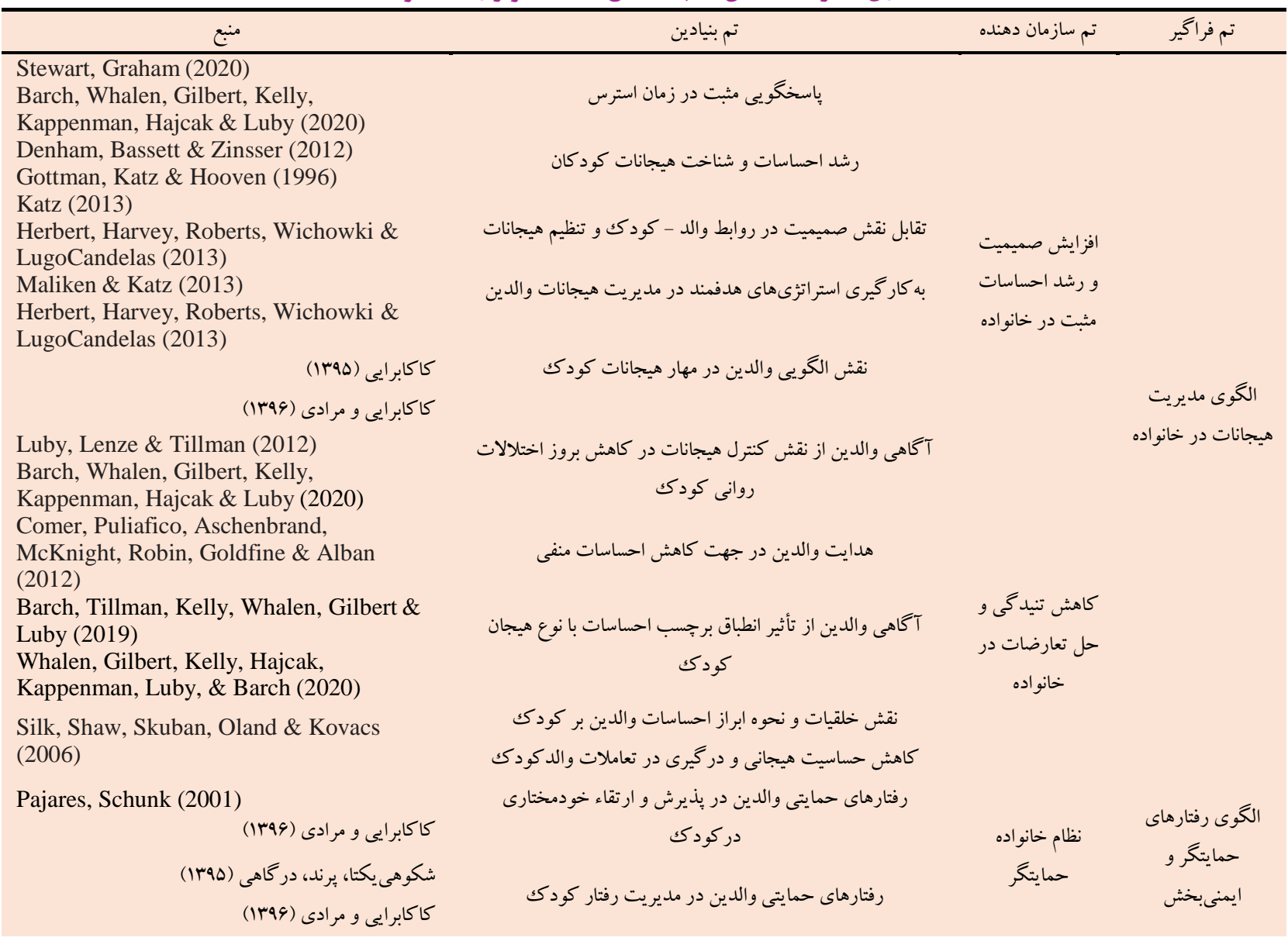


$\frac{\text { منبع }}{\text { Landry, Smith, Miller-Loncar \& Swank }}$ (1997)

$$
\text { ميرزايى كوتنايى، شاكرىنيا و اصغرى (2009) (1) (1) }
$$

Stephens, (2009)

LaFreniere \& Sroufe (1985)

Elicker, Englund \& Sroufe (1992)

Cillessen, Antoniur \& Mayeux (2004)

Donovan, Stoyles \& Berry (2010)

$$
\text { عيسىنزاد، قاسمى وخندان (1) (1) }
$$

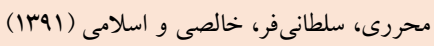

Johnston \& Mash (2001)

Zhang (2011)

Sroufe \& Fleeson (1988)

Sroufe, Fox \& Pancake (1983)

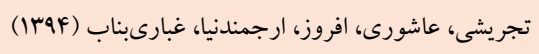

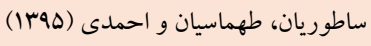

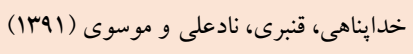

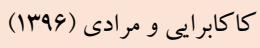

Sexton (2019)

Stright, Neitzel, Sears, Hoke-Sinex (2001)

Maher, Marcynyszyn, Corwin \& Hodnett (2011)

Mei-Ju, Chen-Hsin \& Pin-Chen (2014)

اسماعيلزاده كيابانى (rar)

McCabe, Yeh, Lau, Argote \& Liang (2010)

Hart \& Risley (1999)

Pempek \& Lauricella (2017)

Myers \& Pianta (2008)

Miller (2002)

$$
\begin{aligned}
& \text { عيسىنزاد، قاسمى وخندان (1) (1) }
\end{aligned}
$$

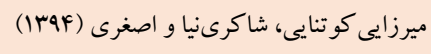

Hood \& Eyberg (2003)

Romanowicz (2019)

Zhang (2011)

O’Connor \& McCartney (2006)

Pianta, Nimetz \& Bennett (1997)

Bretherton (1985)

O’Connor \& McCartney (2006)

Pianta, Nimetz \& Bennett (1997)

Bretherton (1985)

Alessandri (1992)

Myers \& Pianta (2008)

Miller (2002)

$$
\begin{aligned}
& \text { شكوهى يكتا، برند، در گاهى (هوما) } \\
& \text { كاكابرايى (هوس ا) }
\end{aligned}
$$

Comer, Puliafico, Aschenbrand,

McKnight, Robin, Goldfine \& Albano

(2012)

Myers \& Pianta (2008)

$$
\text { ميرزايى كو تنايى، شاكرىنيا و اصغرى (2008) (IFqF) }
$$

Timmer \& Urquiza (2014)

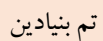

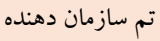

رفتارهاى حمايتى والدين در رشد شناختى - اجتماعى كودكى

$$
\begin{aligned}
& \text { امنيت روانى كودكك در خانو اده و ارتباط مؤثر با همسالان } \\
& \text { ييوند صميميت با احساس امنيت در تعامل والد كودكى } \\
& \text { افزايش امنيت } \\
& \text { روانى در خانو اده } \\
& \text { نخرش مثبت والدين نسبت به كودك و ايجاد محيط عاطفى } \\
& \text { تقويت احساس شايستكى در كود كك بهوسيله يذيرش نامشروط و } \\
& \text { عدم طرد كودكى دود بك } \\
& \text { تقويت اعتمادبهنفس و ايجاد محيطى با حداقل تعارض و مراقبت }
\end{aligned}
$$

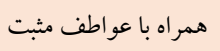

$$
\begin{aligned}
& \text { تطابق انظارات والدين با توانايى كودكى بـ مورك } \\
& \text { عدم طرد كودكى }
\end{aligned}
$$

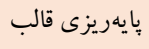

$$
\begin{aligned}
& \text { ذهنى اعتماد و } \\
& \text { دلبستخى ايمن در } \\
& \text { خانواده }
\end{aligned}
$$

$$
\text { متيط شاد و }
$$$$
\text { اهميت ارزش هاى فكرى خانواده و محيط در با يهريزى شخصيت }
$$$$
\text { توجه به ارزشها }
$$

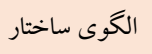

$$
\text { كودكى }
$$

$$
\text { توجه به قوانين در تعاملات والد كودكك }
$$

مسئوليتيذيرى و انعطاف يذيرى والدين در تعامل با كودكك

و قوانين

خانو اد خى

تجلى مهارتهاى اجتماعى و شناختى در تعاملات مثبت والدكودكى بـ برك

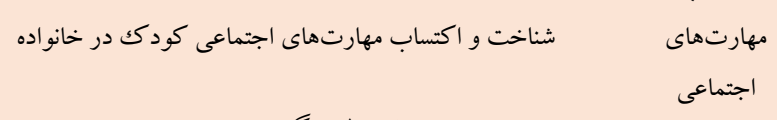$$
\text { ارتباطات گرم و صميمانه }
$$$$
\text { افزايش روابط مثبت در جهت كاهش آسيبهاى روانى كودكى وكيان }
$$

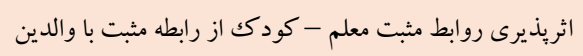

اكتساب

$$
\text { مثبت در خانو اده ارتباطى }
$$

روابط مثبت با

ديخران اثريذيرى شايستخى هاى رفتارى كودك حاصل از تعاملات مطلوب

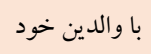

$$
\text { الكو گيرى و تقليد كود كان از رفتار مثبت والدين }
$$$$
\text { الكويذيرى كود كان از اعتمادبهنفس و شجاعت والدين }
$$

$$
\text { كود كان ازيذيرى }
$$$$
\text { الكوى تغيير و }
$$$$
\text { اصلاح رفتار }
$$$$
\text { نقش رفتار والدين در ساز گارى رفتارى كودكى }
$$ 


\begin{tabular}{l}
\hline \multicolumn{1}{c}{ منبع, Janicke, Gray \& } \\
\hline Schuman, Graef, \\
Hommel (2013) \\
Bagner \& Eyberg (2007) \\
Boggs, Eyberg, Edwards, Rayfield, \\
Jacobs, Bagner \& Hood (2004)
\end{tabular}

Damodaran(2013)

Sheperis, Sheperis, Monceaux, Davis \& Lopez (2015)

Pelham \& Fabiano (2008)

Choate, Pincuse, Eyberg \& Barlow (2005)

McCabe, Yeh, Lau, Argote \& Liang (2010)

Samah (2009)

Eyberg (1992)

Greco, Sorrell \& McNeil (2001)

Maher, Marcynyszyn, Corwin \& Hodnett (2011)

Stright, Neitzel, Sears, Hoke-Sinex (2001) Patrikakou, Weissberg, Redding (2005)

Luby, Gilbert, Whalen, Tillman, Barch (2019)

Black, Walker, Fernald, Andersen,

DiGirolamo, Lu \& Devercelli (2017)

Anderson \& Reidy (2012)

Hart \& Risley (1995)

Tamis-LeMonda, Bornstein \& Baumwell (2001)

Sabanathan Wills \& Gladstone (2015)

Burger (2015)

Nesayan, Amani \& Gandomani (2019)

Althof \& Berkowitz (2006)

Tamis-LeMonda, Shannon, Cabrera \& Lamb (2004)

Dodici, Draper \& Peterson (2003)

Fiese (1990)

Slade (1987)

GoLinkoff, Can, Soderstrom \& Hirsh-

Pasek (2015)

Masur, Flynn \& Eichorst (2005)

Tamis-LeMonda, Bornstein \& Baumwell

(2001)

Fowler, Hansen, Barnato \& Garand (2013)

Rhoades, Greenberg, Lanza \& Blair

(2011)

Twerski \& Schwartz (2005)

Jeon \& DeCoster (2013)

Thompson (1984)

Thompson (1984)

Landry, Smith, Miller-Loncar, \& Swank (1997)

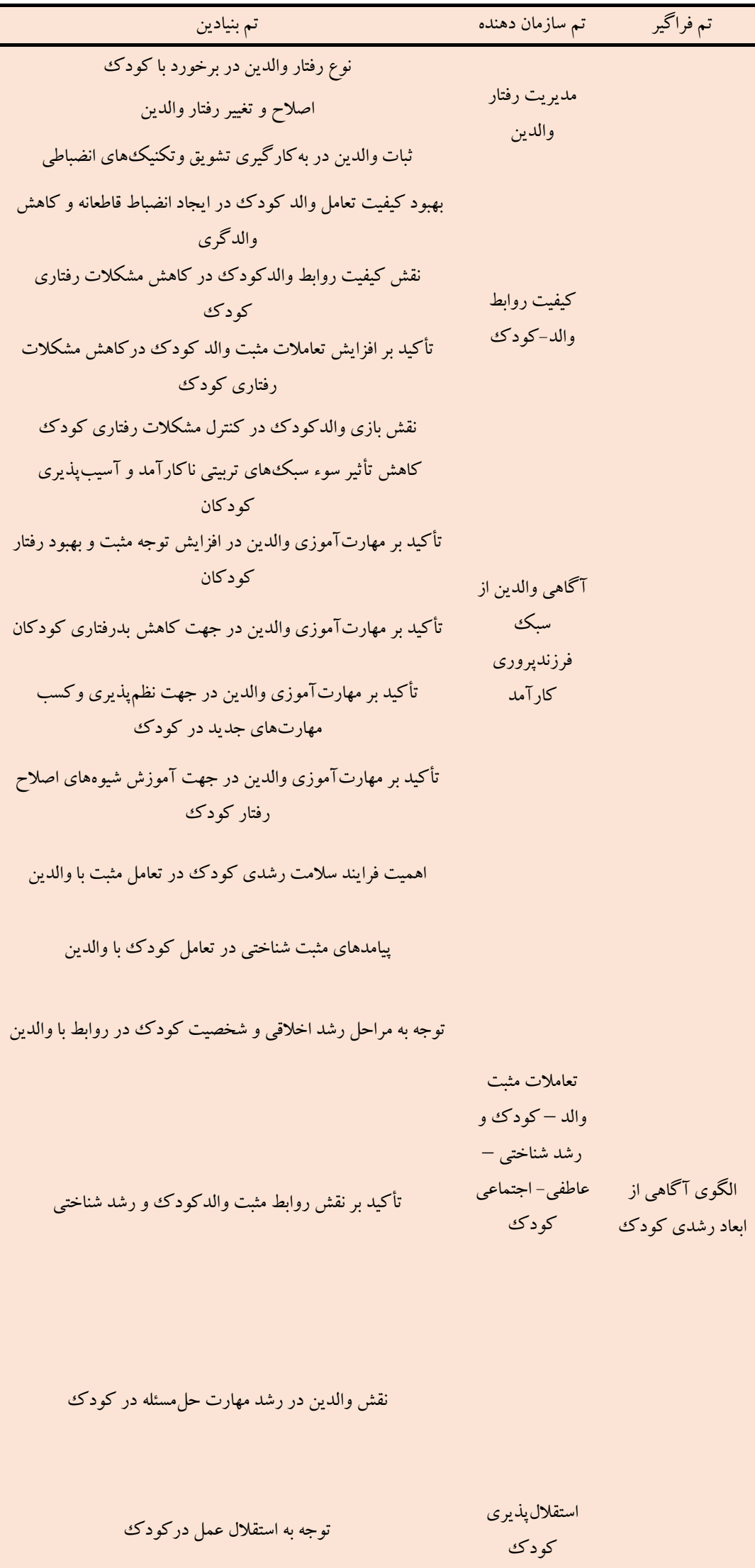




\begin{tabular}{l}
\hline \multicolumn{1}{c}{ منبع } \\
\hline Pempek \& Lauricella (2017) \\
Pempek \& Lauricella (2017) \\
Slade (1987) \\
Ginsburg (2007) \\
Tamis-LeMonda, Bornstein \& Baumwell \\
(2001)
\end{tabular}

McCabe, Yeh, Lau, Argote, Liang (2010)

$$
\text { مهاجرى، يوراعتماد، شكرى و خوشابى (Irar) }
$$

Greco, Sorrell \& McNeil (2001)

Slade (1987)

Fiese (1990)

Pempek, \& Lauricella (2017)

Barr, Zack, Garcia \& Muentener (2008) Lemish, \& Rice (1986)

Wartella, Rideout, Lauricella \& Connell (2013)

Demers, Hanson, Kirkorian, Pempek \& Anderson (2013)

Lavigne, Hanson \& Anderson (2015)

Fender, Richert, Robb \& Wartella (2010)

Gentile, Reimer, Nathanson, Walsh \&

Eisenmann (2014)

Nathanson (2001) (2002)

Nathanson, Sharp, Alade, Rasmussen \&

Christy (2013)

Valkenburg, Piotrowski, Hermanns \&

Leeuw (2013)

Barr, Danziger, Hilliard, Andolina \&

Ruskis (2010)

Valkenburg, Krcmar, Peeters \& Marseille

(1999)

Watson (1999)

Marilyn (2012)

Lickona (1996)

Bulach (2002)

Mei-Ju, Chen-Hsin \& Pin-Chen (2014)

$$
\text { كلانترى و موسوى (2014) (ITAF) }
$$

Luby, Gilbert, Whalen, Tillman, Barch (2019)

Barch, Whalen, Gilbert, Kelly,

Kappenman, Hajcak \& Luby (2020)

Eyberg (1992)

McCabe, Yeh, Lau, Argote \& Liang (2010)

Luby, Gilbert, Whalen, Tillman \& Barch (2019)

Forehand \& Scarboro (1975)

Bondy \& Mash (1999)

Althof \& Berkowitz (2006)
تم فراگير تم سازمان دهنده

نقش بازى هاى والد كو دك در غنىسازى تجربيات و رشد شناختى ني

$$
\text { كودكى }
$$

$$
\begin{aligned}
& \text { نقش بازىهاى والدكود كك در غنى سازى رشد شناختى و زبانى } \\
& \text { كودكى } \\
& \text { نقش بازى در تعاملات والدين، رشد شناختى، اجتماعى، عاطفى و } \\
& \text { جسمى كودك وند } \\
& \text { تسريع رشد شناختى با افزايش فعاليت و بازى كودكى } \\
& \text { مثبت كودكك در بازى } \\
& \text { نقش فعال والدين هنكام بازى با كودكى } \\
& \text { والد كودكى مخصوص كود }
\end{aligned}
$$$$
\text { اهميت بازى در }
$$$$
\text { رشد جسمى - رمبت باري }
$$$$
\text { شناختى و }
$$$$
\text { اجتماعى كودكى }
$$

$$
\begin{aligned}
& \text { تأكيد بر نقش رسانههاى مخصوص كود كان در هدايت گرى كلامى } \\
& \text { غنى سازى اوقات } \\
& \text { و شناختى كو دكان }
\end{aligned}
$$

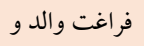

$$
\begin{aligned}
& \text { كودكك }
\end{aligned}
$$

الكوى فرزنديرورى

مثبت

$$
\begin{aligned}
& \text { نقش وقت گذراندن و اوقات فراغت در توانايى تفكر و حل مسئله } \\
& \text { در كود كان } \\
& \text { بالا بردن كيفيت تعاملات بهوسيله وقت گذراندن با كودكى } \\
& \text { تشويق كودكك و } \\
& \text { كاهش واكنشهاى تنبيهى } \\
& \text { افزايش توجه مثبت و ناديده كرفتن رفتار منفى كودكى } \\
& \text { توجه مثبت به كودك و افزايش ياداشهاى كلامى - عاطفى } \\
& \text { اهميت مهارتهاى فرزنديرورى در رشد عواطف كودكى } \\
& \text { انعطاف يذيرى } \\
& \text { انعطاف يذيرى بيشتر والدين در برخورد با كودكى } \\
& \text { نقش خود كار آمدى والدين در انعطافيذيرى در رفتار با كودك } \\
& \text { توجه به افكار و احساسات و نظرات كودكى }
\end{aligned}
$$




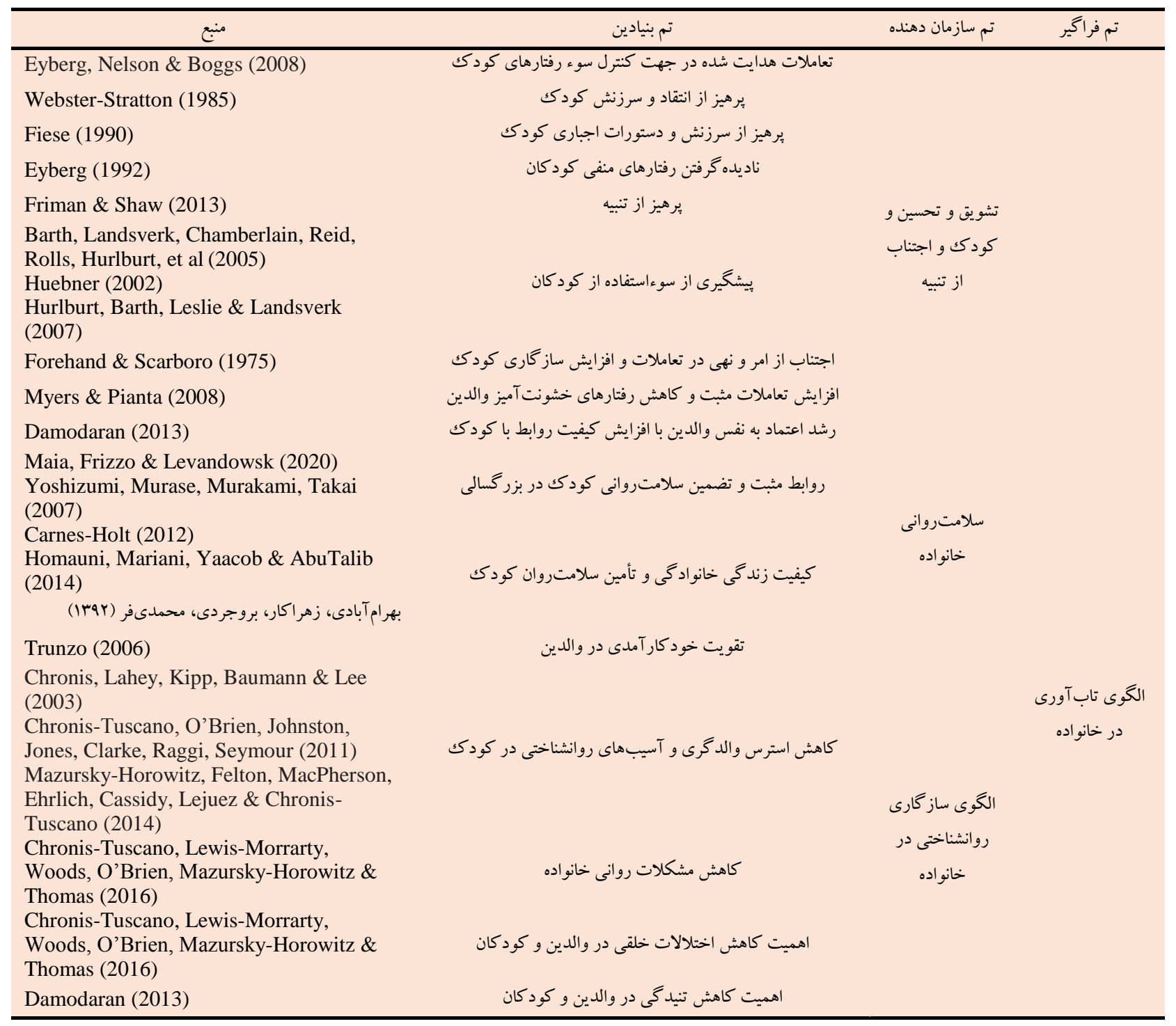

هفده تم يايه دارد. 9. آكاهى از الكوى ابعاد رشدى كودك كه از سه تم سازماندهنده و دوازده تم يايه تشكيل شده است. V. الكوى فرزنديرورى مثبت كه سه تم سازماندهنده و دو تم يايه را دارا مىباشد. ^ـ الكوى تابآورى در خانواده كه دو تم سازماندهنده و هشت تم پايه از آن

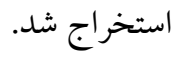
يس از تشكيل قالب مضامين، الكوى تعاملات والد - كودكى تدوين شد كه در شكل آ آمده است.
نتايج جدول ا الكوى تعاملات مؤثر والد - كودكك را نشان مىدهد. بر اساس تحليل تماتيكك، هشت مضمون فراكير به دست آمد كه هر كدام شامل مؤلفههاى سازماندهنده و يايه نيز مىباشند. تمهاى فراكير و حوزههاى مورد بوشث آنها به شرح زير است: ا. الكوى مديريت هيجانات در خانو اده كه از دو تم سازماندهنده و ده تم يايه تشكيل شده است. r. الكوى رفتارهاى حمايتخر و ايمنى بخش كه سه تم سازماندهنده و ده تم يايه دارد. r. ساختار محيطى منعطف در خانواده كه دو تم سازماندهنده و ينج تم بايه را دارا مىباشد. F. الكوهاى ارتباطى مثبت در خانواده نيز عبارت از دو تم سازماندهنده و شش تم يايه است. ه. به كارگيرى الكوى تغيير و اصلاح رفتار كه جهار تم سازماندهنده و 


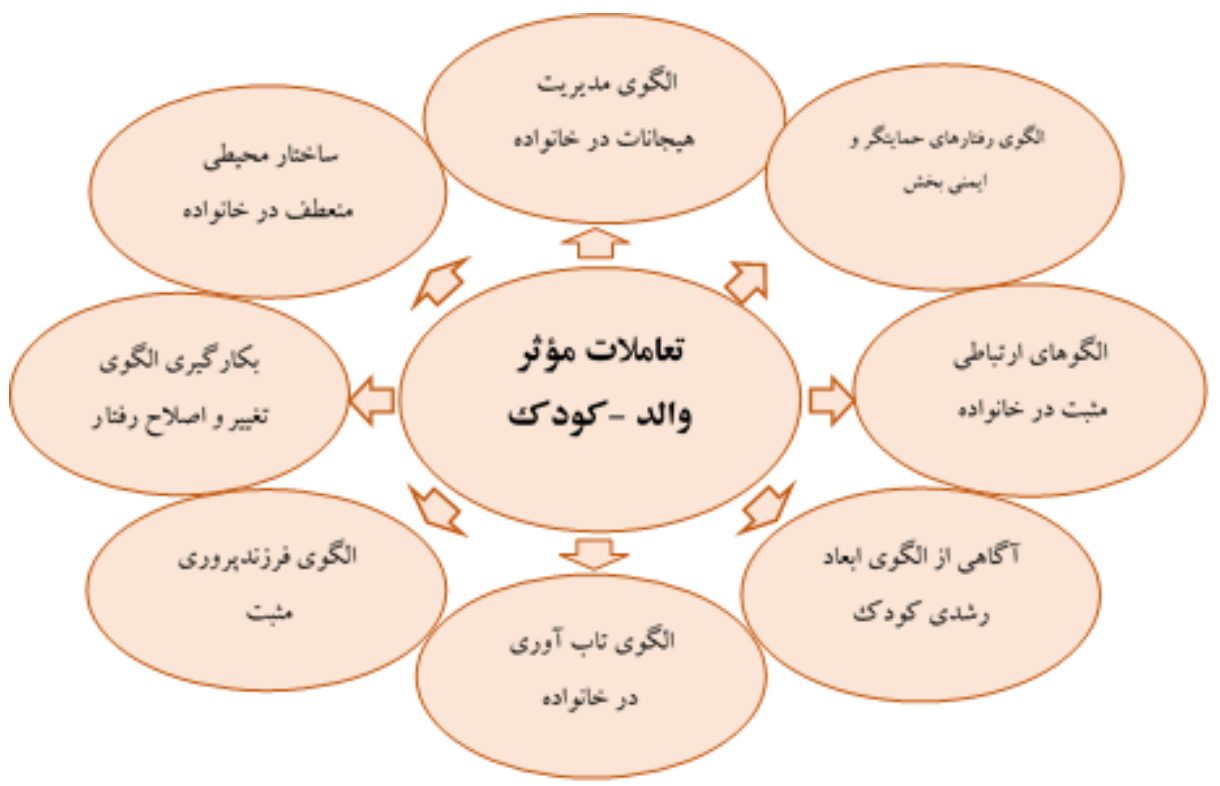

شكل ا. الكوى تعاملات مؤثر والد - كودك ويثه كود كان بيش از دبستان (ع تا ح سال)

بدين منظور توافق ارزيابان مبنى بر صحت يافتها حاصل شد و كارشناسان،

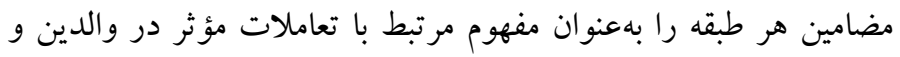

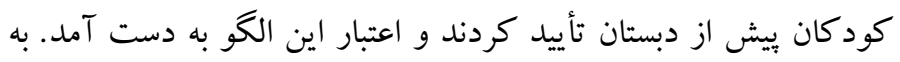

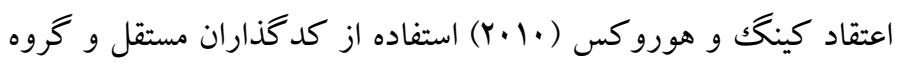
خبر گانّا، فر آيندى رايج براى ارزيابى و كنترل كيفيت تحليل هاى مضمون است كه مشابه محاسبه آمارى قابليت اطمينان درونى در تحليل محتواى درى

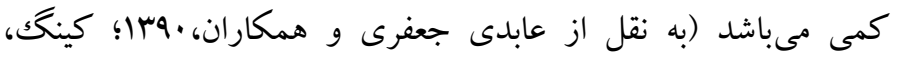

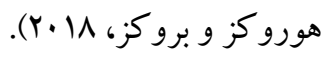

\section{بحث و نتيجه Fيرى}

هدف از يزوهش حاضر تدوين الكوى تعاملات مؤثر والد - كودك وئزئه

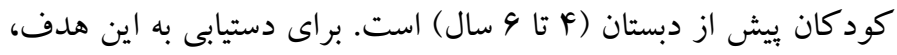
كليه متون نظرى در دسترس كه با موضوع مورد نظر مرتبط بودند مورد

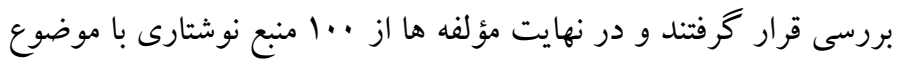

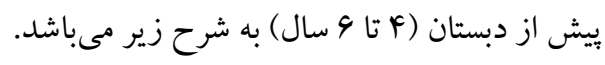
الكوى مديريت هيجانات در خانواده: در تبيين اين مضمون مىتوان به اين نكته اشاره نمود كه ازآنجايى كه والدين نقش مؤثرى در هدايت و بروز احساسات مثبت يا منفى در كود كان خود دارند (كامر و همكاران،

3. Independent Coders and Expert Panels
اعتبارسنجى التو الكوى تعاملات مؤثر والد - كودكى ويزه كودكان بيش از دبستان (F تا و سال) تم فراگير شامل الكوى مديريت هيجانات در خانواده، الكوى ولى

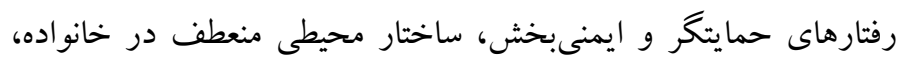

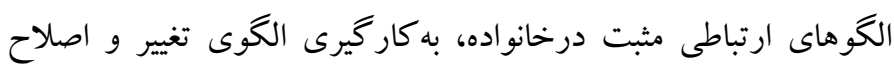

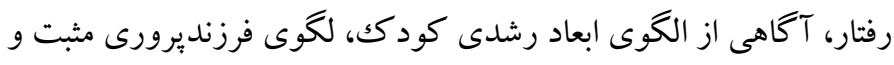

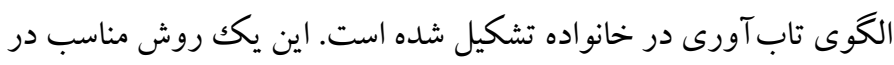

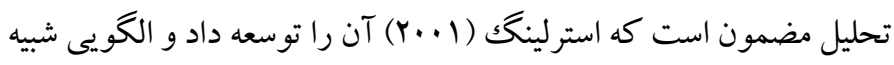
تارنما ارائه داد و نشان از ارتباط ميان سطوح مضامين مىباشد

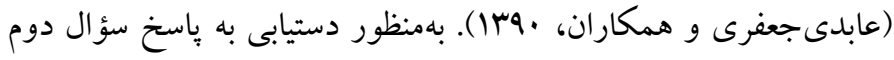

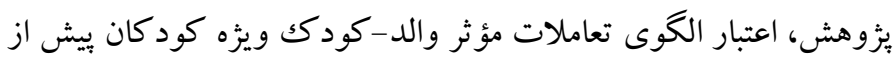

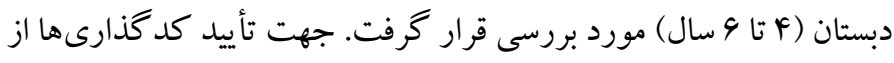
روش خودبازبينى محقق و قابل اعتماد بودن، توسط جهار يُورهشخر

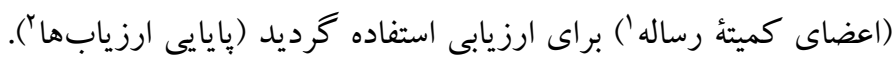

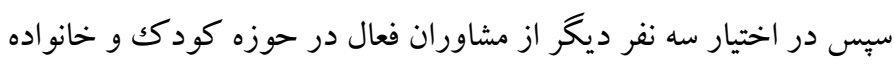

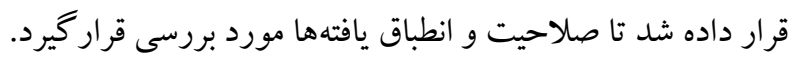

${ }^{2}$. Inter-rater reliability
' نويسنده اول، اساتيد راهنما و مشاور در يثزوهش حاضر

. 
فراوان است. اين عوامل در تعاملات مؤثر والد و كودك تأثير شخرف بر جاى مى كذارد. ساختار محيطى منعطف در خانواده: آنارد آنجايى كه خانو اده اولين بايه كذار شخصيت و ارزشهاى فكرى در افراد است، نقش مهمى در تعيين

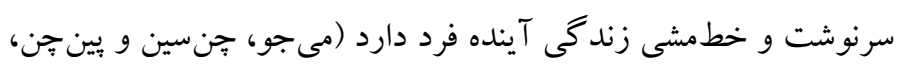

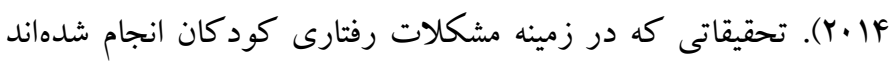

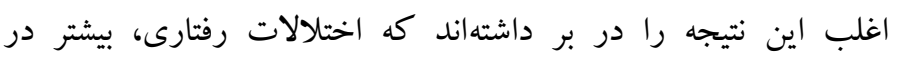

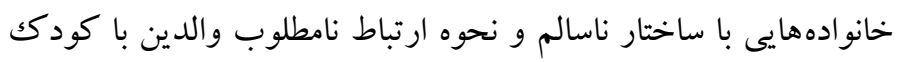

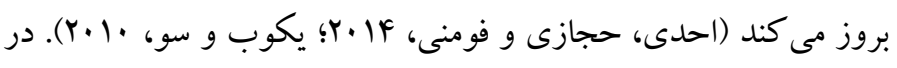

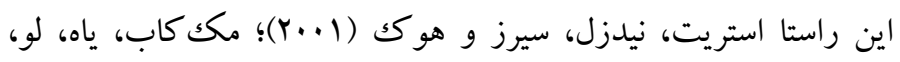

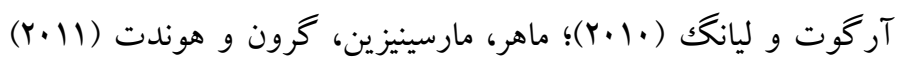
معتقدند فراهم كردن محيط آموزشى غير رسمى در خانو ادهه، باعث علاقه

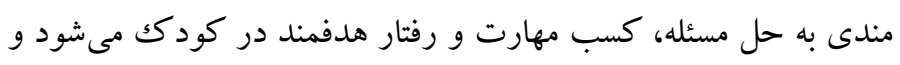

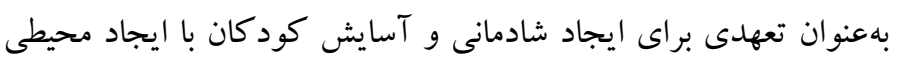

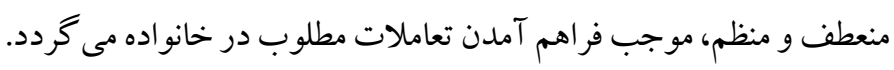

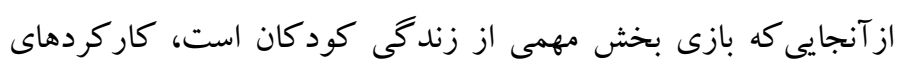

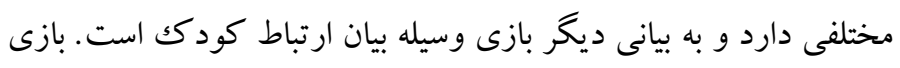

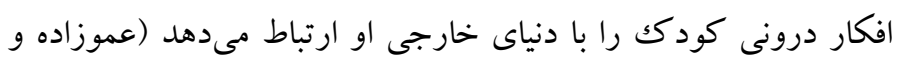

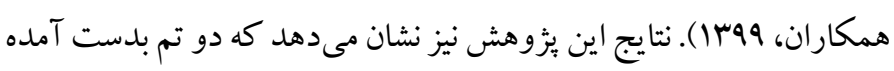

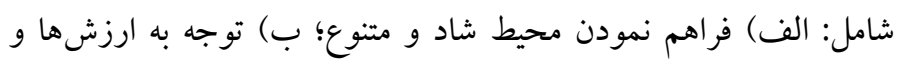

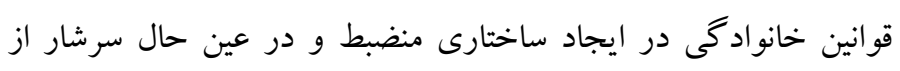

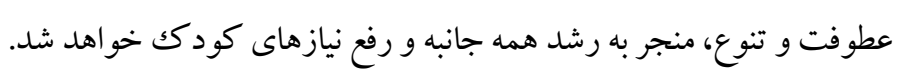

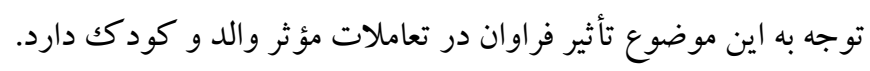

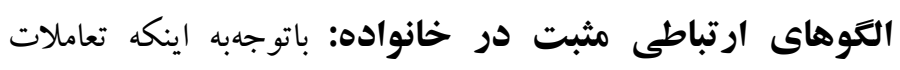

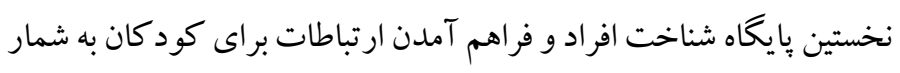

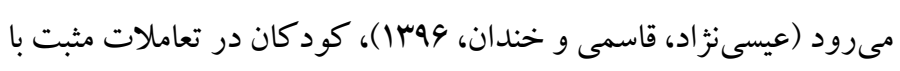

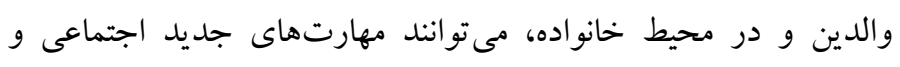

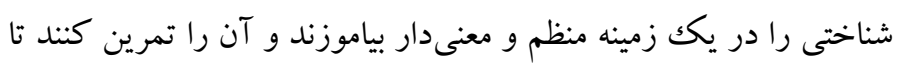

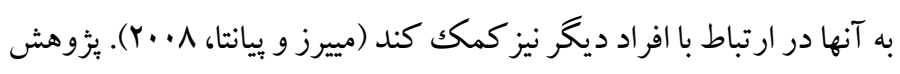

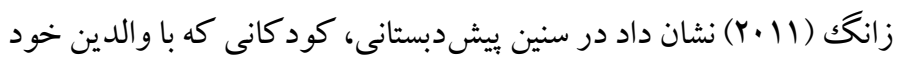

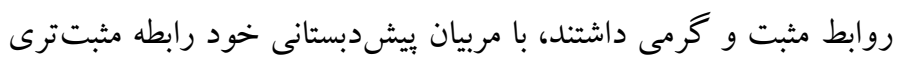

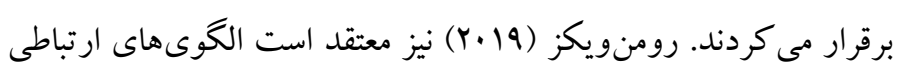

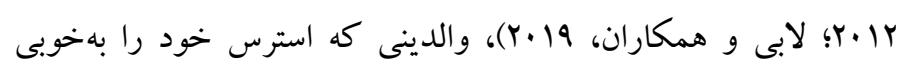

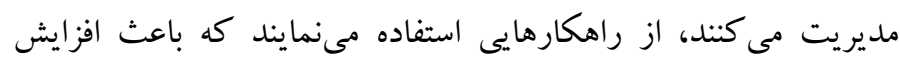

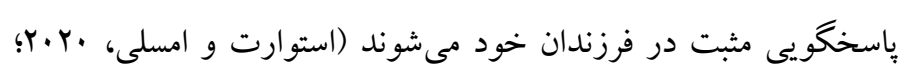

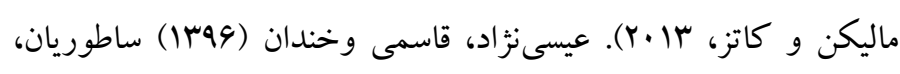

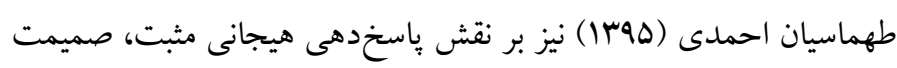

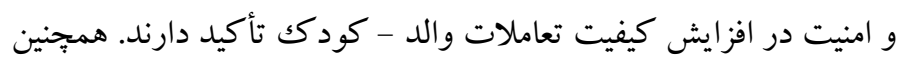

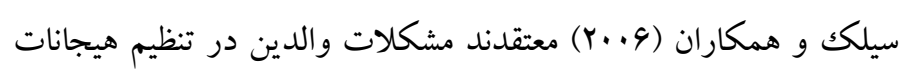

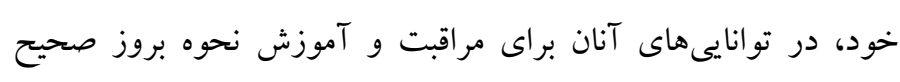

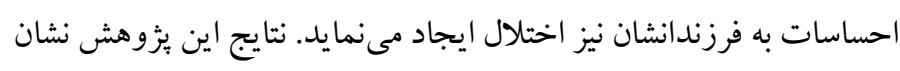

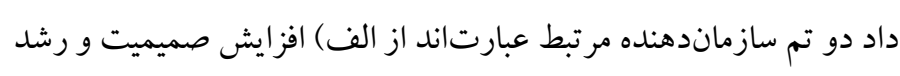

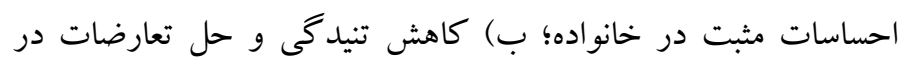

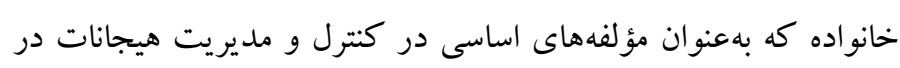
تعاملات والدين و كود كك مؤثر است.

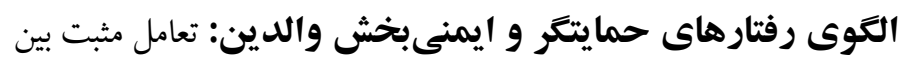

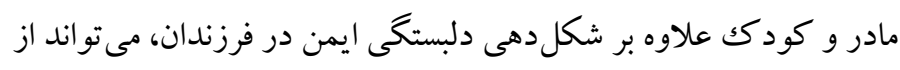

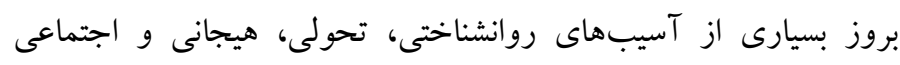

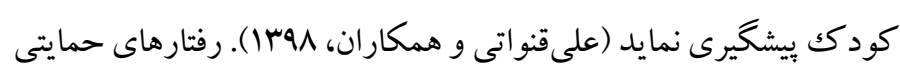

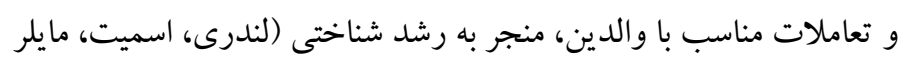

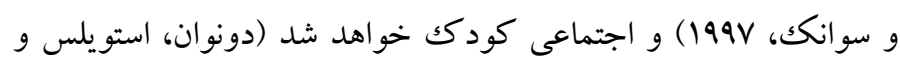

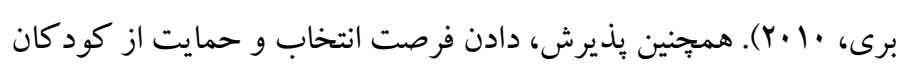

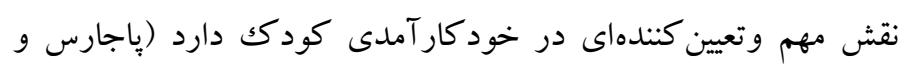

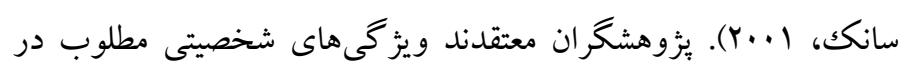

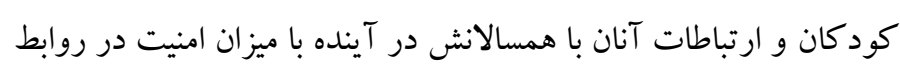

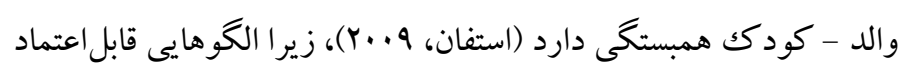

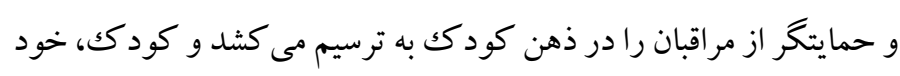

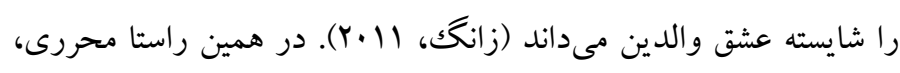

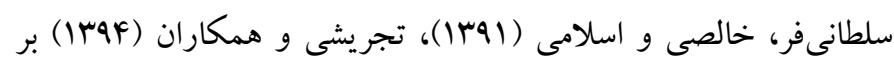

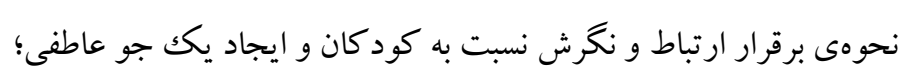

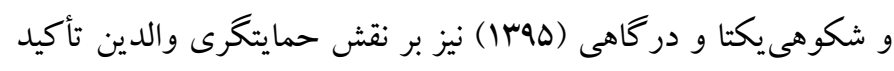

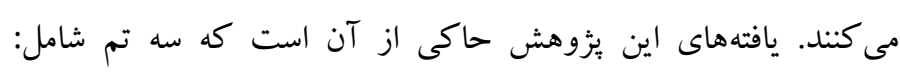

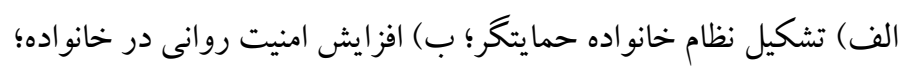

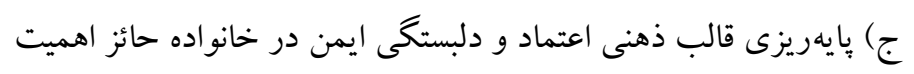


كودكى از جمله شناخت، مهارتهاى زبانى، شايستخىهاى اجتماعى و

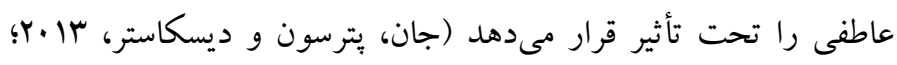

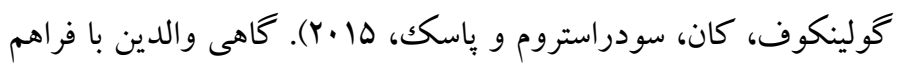
نمودن تجربيات غنى بازى، رشد شناختى در كود كان را تقويت مى كنيند

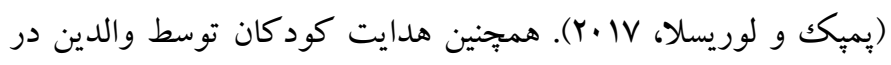

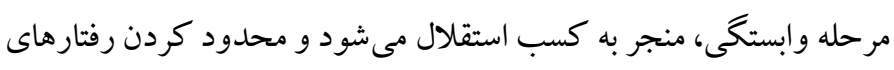
كود كان، با كندى در رشد شناختى و اجتماعى او همر اه خواهد بو بود. با توجه به نتايج بزوهش حاضر، سه تم سازماندهنده عبارت از الف) اهميت

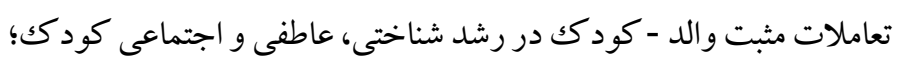

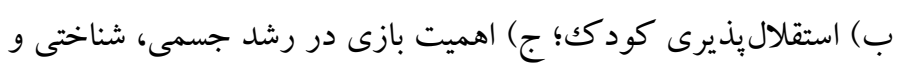

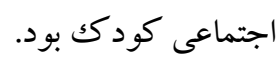
الكوى فرزنديرورى مثبت: آموزش شيوههاى مثبت فرزنديرورى به والدين و افزايش تشويق با بيانات عاطفى، بهعنوان روشى براى مقابله با ميا احساسات منفى و كاهش واكنشهاى تنبيهى در كودكان بكار مىرود

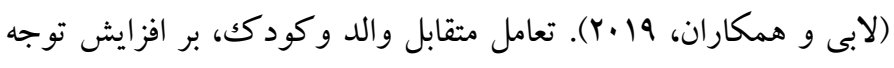

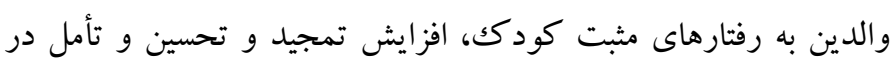

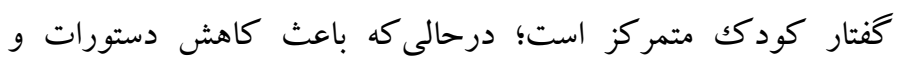

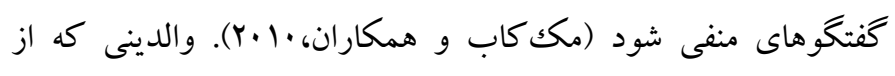

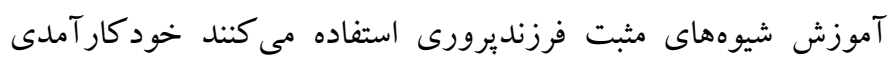

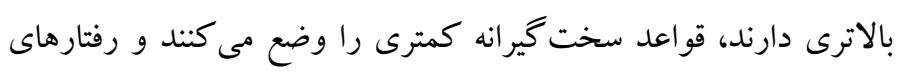

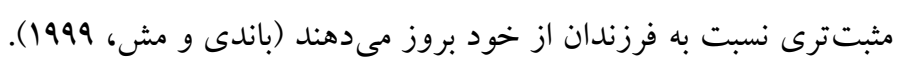

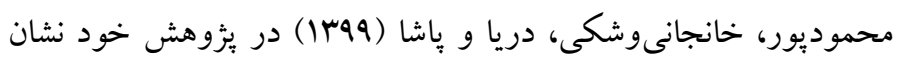
دادند كه سبككهاى فرزنديرورى، خود كار آمدى ادراككشده و تنظيم

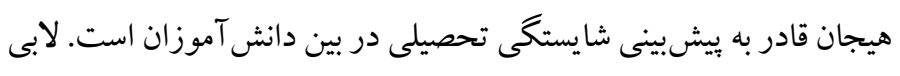

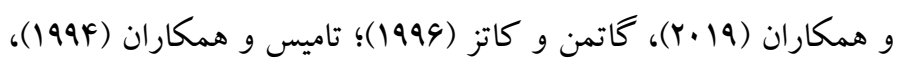

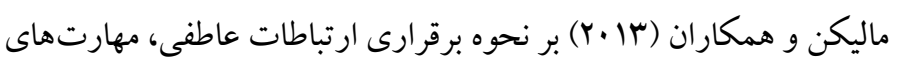

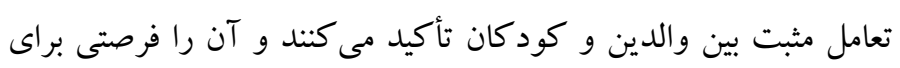
تمرين و كسب مهارتهاى جديد در كودكك بهشمار مى آورند. نتايج يثزوهش حاضر حاكى از آن است كه سه تم سازمان دهنده شامل:

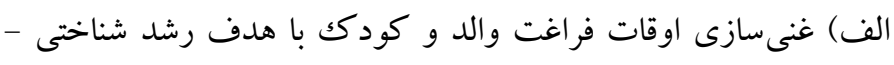

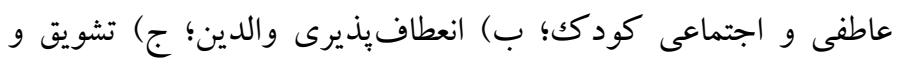

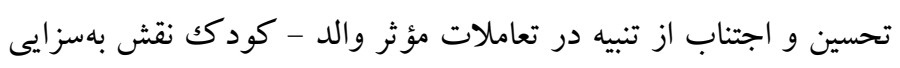

مثبت، كود كان سنين ييش از دبستان كه داراى مشكلات رفتارى قابل توجه

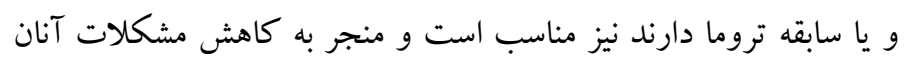

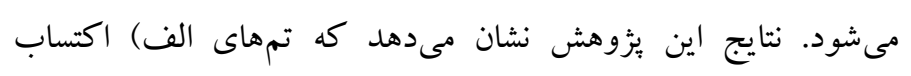

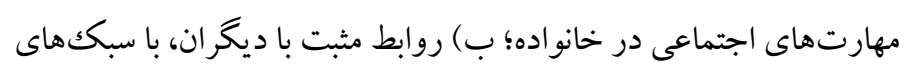

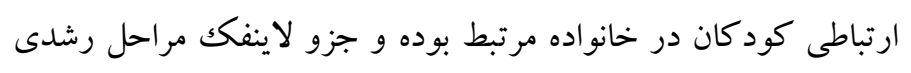
كود كك در زمينههاى اجتماعى مىباشد كه از عو امل مهم در تعاملات مؤثر والد و كود كك است.

بل كاركيرى الكوى تغيير و اصلاح رفتار: تحقيقات نشان مىدهند

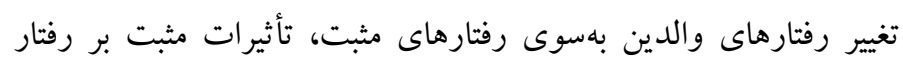

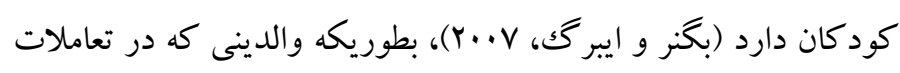

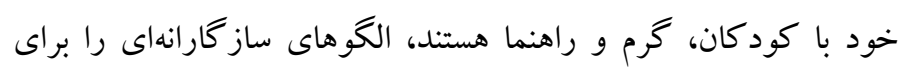

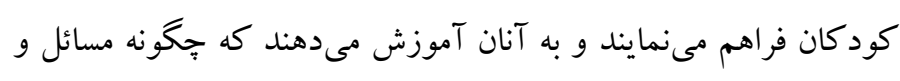

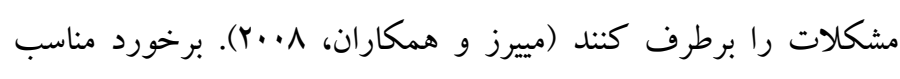

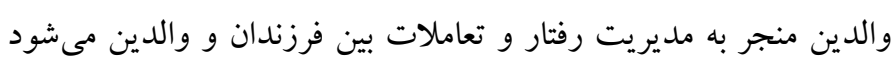

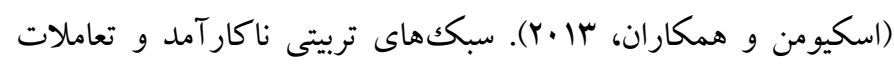
نامناسب ميان والدين و كود كان، در طول دوران رشد به ايجاد مشكلات

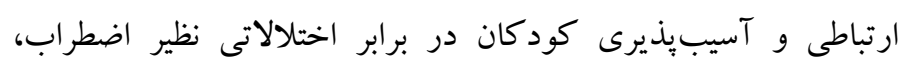
مشكلات رفتارى و آسيبروانى منجرخواهد شد (مفرد، عبدالله و سماح،

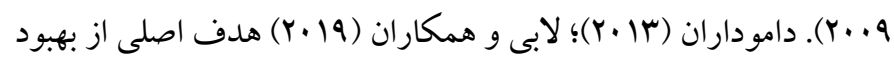

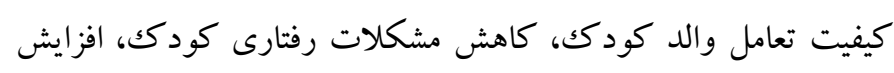
رفتارهاى موافق اجتماعى است. نتايج اين بثزوهش نيز نشان مىدهد كه

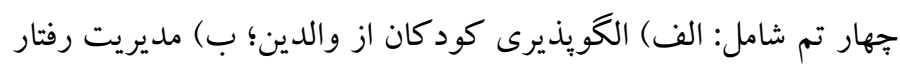

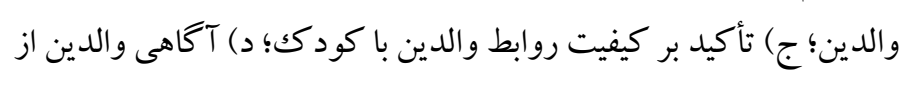
سبكهاى فرزنديرورى در جهت تغيير و اصلاح رفتار در خانواده و تعاملات مؤثر والد و كودكك مؤثر است. آكاهى از الكوى ابعاد رشدى كودك: اين مضمون ازاينجهت وته

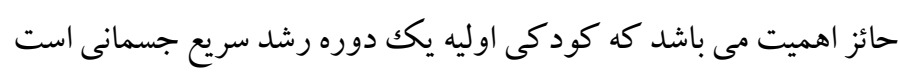

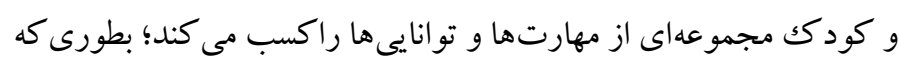

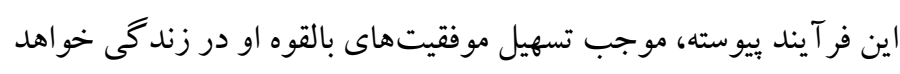

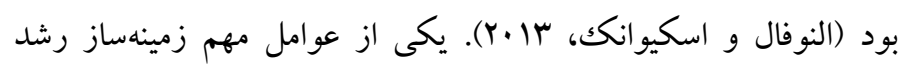

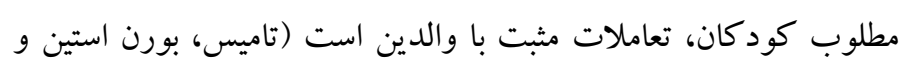

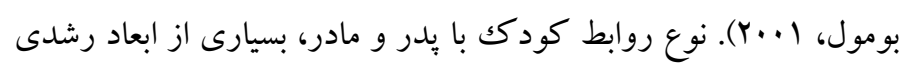




\section{مىشود.}

محدوديت هايى نيز در اين يثوهش وجود داشته است. از آن جمله مى توان

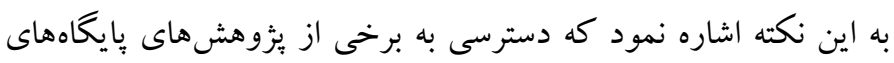

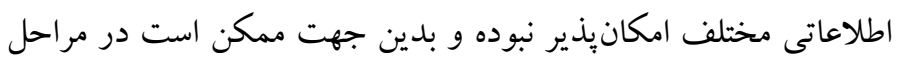

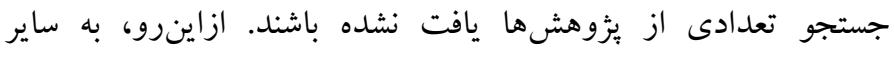

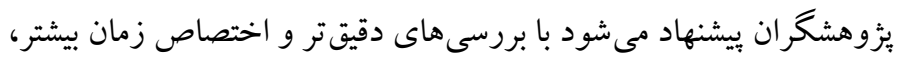

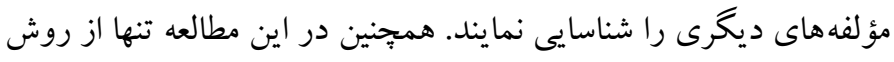

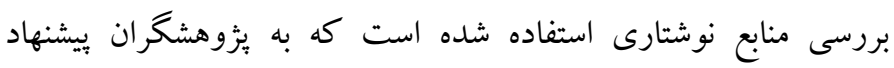

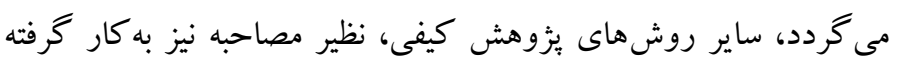

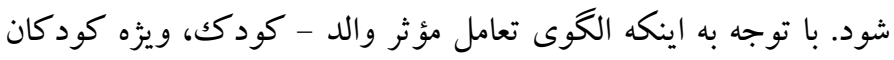
ييش از دبستان از مؤلفههاى كاربردى برخوردار است، توجه به به آن،

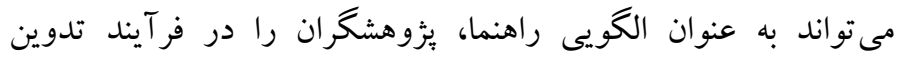

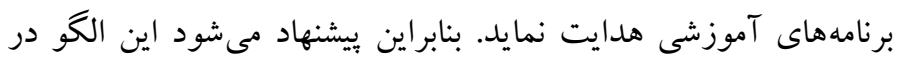

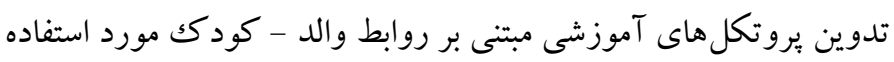

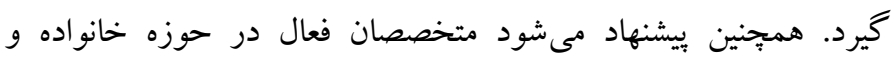

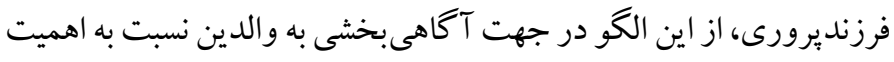
تعاملات والد - كود كك استفاده نمايند.

ملاحضات اخلاقى وبيروى از اصول اخلاق ئوهش: إين مقاله بر خر فته از رساله دكترى نويسنده اول در

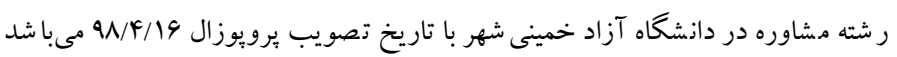

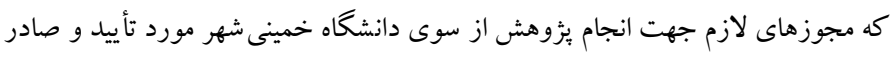

شده است.

حامى مالى: اين بثوهش در قالب رساله دكترى و بدون حامى مالى مىباشد.

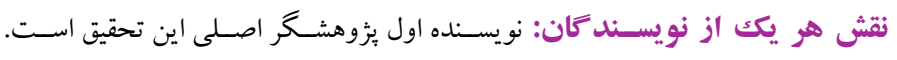

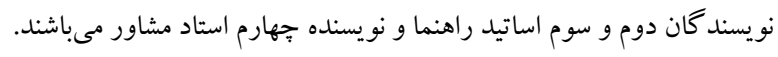
تضاد منافع: نو يسند كان در اين يُوهش هيج كونه تضاد منافعى را را اعلام نمىنمايند.

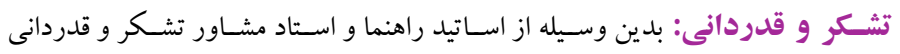
مى گردد.
الكوى تابآورى در خانواده: بهبود كيفيت تعاملات والدين و كودكان، در ييشگيرى از ايجاد تنش در روابط آنان و افزايش اعتماد به نه نفس افراد در خانواده، راهكارى مناسب و اساسى است (داموداران،

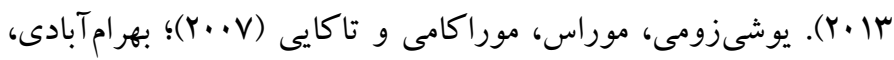

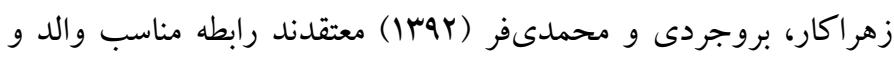

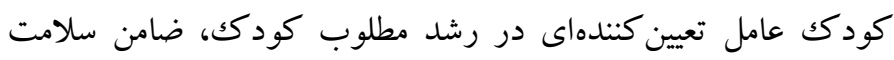

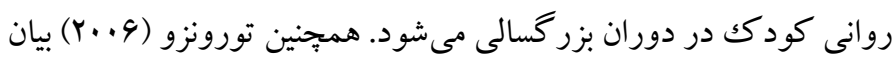

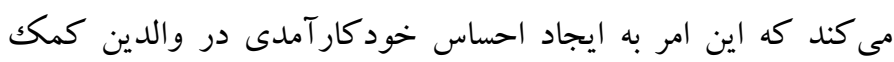
مى كند. علاوه بر آن تقويت روابط والدين و فرزندان منجر به به بهبود علائم برخى از اختلالات كود كان از قبيل نافرمانى مقابلهاى، سلو كك و نيز كاهش

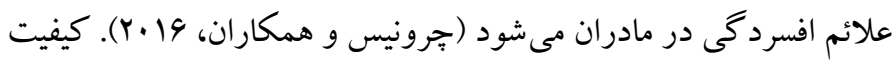

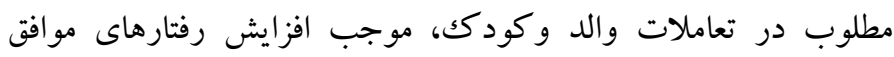

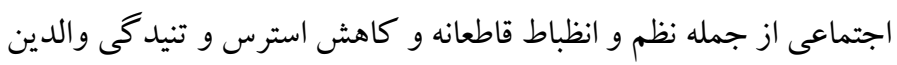

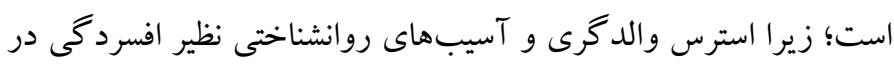
والدين كود كان داراى مشكلات رفتارى شايعتر است (مازورسكى و و ونسي

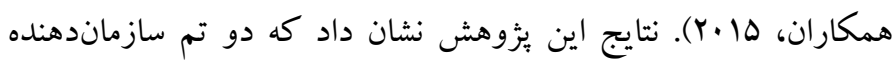

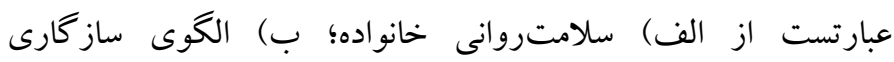
روانشناختى در خانو اده كه با الكوى تاب آورى در خانواده مر تبط است.

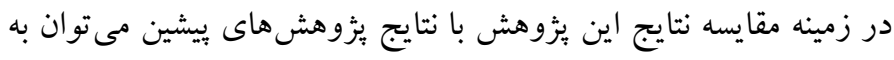

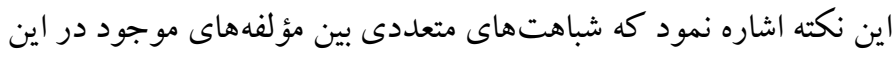

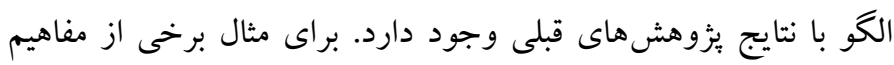

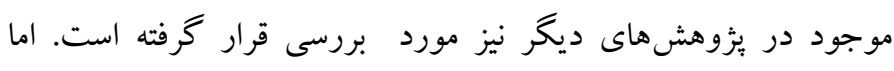

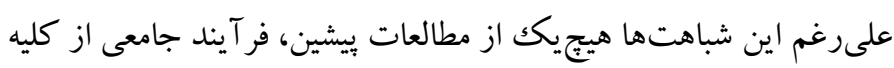

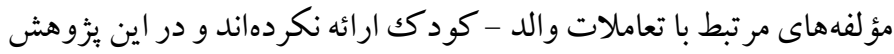
سعى شده است الكَوى نسبتاً جامع و داراى اعتبار كافى در اين زمينه تدوين كردد. در مجموع، تدوين الكوى تعاملات مؤثر والد - كودكى ويزٔه

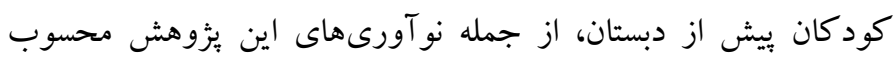




\section{References}

Almukhambetova, A., \& Hernández-Torrano, D. (2020). Gifted students' adjustment and underachievement in university: An exploration from the selfdetermination theory perspective. Gifted Child Quarterly, 64 (2), 117-131. [Link]

Al Nofal, A., \& Schwenk, W. F. (2013). Growth failure in children: a symptom or a disease? Nutrition in Clinical Practice, 28(6), 651-658. [Link]

Anderson, P. J., \& Reidy, N. (2012). Assessing executive function in preschoolers. Neuropsychology review, 22(4), 345-360. [Link]

Attride-Stirling, J. (2001). Thematic networks: an analytic tool for qualitative research. Qualitative research, 1(3), 385-405. [Link]

Aslani, K., Varasteh, M., Amanelahi, A. (2016). Effectiveness of positive parenting program training on parent-child interaction quality. Counseling Culture and Psycotherapy, 7(28), 183-201. [Link]

Amouzadeh F, honarmand P, Rahimzadeh M, Gharayagh zandi H, Rostami R. (2020). The impact of fifa on the ADHD symptoms in students with ADHD. Journal of Psychological Science. 19(93). 10491058. [Link]

Azizi, A., Fatehizade, M., Ahmadi, A., Jazayeri, R. (2018). Effect of child-parent relationship therapy on parenting stress and empowerment of parents with children with Attention Deficit / Hyperactivity Disorder. Family Counseling and Psychotherapy, 8(1), 27-46. [Link]

Ali Ghanavati, S., Sharifi, T., Ghazanfari, A., Abedi, M., Taghavi, A. (2019). Effectiveness of Parent-Child Interaction Educational Package on Attachment Quality of Children with Inadequate Mother-Child Interaction. Empowering Exceptional Children, 10(2), 237-249. [Link]

Abedi Ja'fari, H., Taslimi, M., Faghihi, A., Sheikhzade, M. (2011). Thematic Analysis and Thematic Networks: A Simple and Efficient Method for Exploring Patterns Embedded in Qualitative Data Municipalities). Strategic Management Thought, 5(2), 151-198. [Link]

Black, M. M., Walker, S. P., Fernald, L. C., Andersen, C. T., DiGirolamo, A. M., Lu, C., \& Devercelli, A. E. (2017). Early childhood development coming of age: science through the life course. The Lancet, 389(64), 77. [Link]

Bjorseth, A., \& Wichstrøm, L. (2016). Effectiveness of parent-child interaction therapy (PCIT) in the treatment of young children's behavior problems. A randomized controlled study. PloS one, 11(9), 13. [Link]

Bussing, R., Nelson, M. M., \& Kurtz, S. (2016). ParentChild Interaction Therapy: Treatment Components and Evidence-Base. Journal of the American Academy of Child \& Adolescent Psychiatry, 10(55), 351. [Link]

Burger, K. (2015). Effective early childhood care and education: Successful approaches and didactic strategies for fostering child development. European Early Childhood Education Research Journal, 23(5), 743-760. [Link]

Braun, V., \& Clarke, V. (2006). Using thematic analysis in psychology. Qualitative research in psychology, 3(2), 77-101. [Link]

Bondy, E. M., \& Mash, E. J. (1999). Parenting Efficacy, Perceived Control over Caregiving Failure, and Mothers' Reactions to Preschool Children's Misbehavior. Child Study Journal, 29(3), 157-73. [Link]

Bagner, D. M., \& Eyberg, S. M. (2007). Parent-child interaction therapy for disruptive behavior in children with mental retardation: A randomized controlled trial. Journal of Clinical Child and Adolescent Psychology, 36(3), 418-429. [Link]

Bratton, S. C., \& Landreth, G. L. (2019). CPRT Training Resources. In Child-Parent Relationship Therapy (CPRT) Treatment Manual (pp. 177-188). Routledge. [Link]

Chronis-Tuscano, A., Lewis-Morrarty, E., Woods, K. E., O’Brien, K. A., Mazursky-Horowitz, H., \& Thomas, S. R. (2016). Parent-child interaction therapy with emotion coaching for preschoolers with attention-deficit/hyperactivity disorder. Cognitive and Behavioral Practice, 23(1), 62-78. [Link]

Comer, J. S., Puliafico, A. C., Aschenbrand, S. G., McKnight, K., Robin, J. A., Goldfine, M. E., \& Albano, A. M. (2012). A pilot feasibility evaluation of the CALM Program for anxiety disorders in early childhood. Journal of anxiety disorders, 26(1), 4049. [Link]

Carnes-Holt, K. (2012). Child-parent relationship therapy for adoptive families. The Family Journal, 20(4), 419-426. [Link]

Denham, S. A., Bassett, H. H., \& Zinsser, K. (2012). Early childhood teachers as socializers of young children's emotional competence. Early Childhood Education Journal, 40(3), 137-143. [Link]

Donovan, M., Stoyles, G., \& Berry, L. S. (2010). Postseparation parenting education in a family 
relationship centre: a pilot study exploring the impact on perceived parent-child relationship and acrimony. Journal of Family Studies, 16(3), 224. [Link]

Domoff, S. E., \& Niec, L. N. (2018). Parent-child interaction therapy as a prevention model for childhood obesity: A novel application for high-risk families. Children and Youth Services Review, 91, 77-84. [Link]

Day, L. A., Costa, E. A., Previ, D., \& Caverly, C. (2018). Adapting parent-child interaction therapy for deaf families that communicate via American Sign Language: A formal adaptation approach. Cognitive and Behavioral Practice, 25(1), 7-21. [Link]

Dalvand H, Rassafiani M, Bagheri H. (2014). Family Centered Approach: A literature the review. $m r j .8$ (1):1-9. [Link]

GoLinkoff, R. M., Can, D. D., Soderstrom, M., \& HirshPasek, K. (2015). (Baby) talk to me: the social context of infant-directed speech and its effects on early language acquisition. Current Directions in Psychological Science, 24(5), 339-344. [Link]

Homauni, M., Mariani, B. M., Yaacob, S. N., \& AbuTalib, M. (2014). Parent-child relationship and aggression among adolescents in Tehran, Iran. Life Science Journal, 11(9), 766-70. [Link]

Herschell, A. D., Scudder, A. B., Schaffner, K. F., \& Slagel, L. A. (2017). Feasibility and effectiveness of parent-child interaction therapy with victims of domestic violence: A pilot study. Journal of child and family studies, 26(1), 271-283. [Link]

Isanejad. O., Ghasemi, S. Y, Khandan, F. (2017). Examining the Factor Structure and Reliability of the Parent-Child Interaction Questionnaire (PACHIQ) among High School Students. Family Research 13(2): 251-272. [Link]

Jeon, H. J., Peterson, C. A., \& DeCoster, J. (2013). Parentchild interaction, task-oriented regulation, and cognitive development in toddlers facing developmental risks. Journal of Applied Developmental Psychology, 34(6), 257-267. [Link]

Kimber, M., McTavish, J. R., Luo, C., Couturier, J., Dimitropoulos, G., \& MacMillan, H. (2019). Mandatory reporting of child maltreatment when delivering family-based treatment for eating disorders: A framework analysis of practitioner experiences. Child abuse \& neglect, 88, 118-128. [Link]

King, N., Horrocks, C., \& Brooks, J. (2018). Interviews in qualitative research. SAGE Publications. 2 nd Edition. p215. [Link]
K Damodaran, D. (2015). Parent Child Interaction Therapy (PCIT): Child well-being through an effective parenting intervention. Asian J. Nursing and Research. 3(1). 37-39. [Link]

King, N., \& Horrocks, C. (2010). Interviews in qualitative research. London: Sage. [Link]

Kakabaraee, K. (2016). The effect of family oriented problem solving curriculum education on parentchild relationship elementary School Students. Counseling Culture and Psycotherapy, 7(26), 6185. [Link]

Kakabaraei, K., moradi, A. (2017). family oriented problem solving training to parents and the impact on the child's perception of parents. Counseling Culture and Psycotherapy, 8(29), 165-185. [Link]

Karimi E, DashtBozorgi Z. (2019). Effectiveness of Parent-Child Interaction Group Training on Behavioral Problems and Mother-Child Relationship in Mentally Retarded Children. Iranian Journal of Psychiatric Nursing (IJPN). 7 (5):36-43. [Link]

Landry, S. H., Smith, K. E., Miller-Loncar, C. L., \& Swank, P. R. (1997). Predicting cognitive-language and social growth curves from early maternal behaviors in children at varying degrees of biological risk. Developmental psychology, 33(6), 1040. [Link]

Mahmoudpour A, Darba M, Khanjani Veshki S, Pasha S. (2020). Predicting student's academic competence based on parenting styles, perceived self-efficacy and emotion regulation. Journal of Psychological Science. 19(93). 1115-1124. [Link]

Masomi, M., Etemadi, O., Ahmadi, S. (2013). The effectiveness of integrative group training approach (positive parenting program and behavior therapy) to improve mother child relationship. Research in Clinical Psychology and Counseling. 2(2).117-132. [Link]

Mirzaei F, Shakerinia I, Asghari F. (2016). The Associations between Parent-Child Relationship and Aggressive Behavior among Students. J Child Ment Health. 2(4). 21-34. [Link]

Maia, G. N., Frizzo, G. B., \& Levandowski, D. C. (2020). Psychofunctional symptoms in infants of young mothers: Association with maternal mental health and parental bonding. Early Human Development, 141, 104938. [Link]

Mei-Ju, C., Chen-Hsin, Y., \& Pin-Chen, H. (2014). The beauty of character education on preschool children's parent-child relationship. Procedia- 
Social and Behavioral Sciences, 143, 527-533. [Link]

Maliken, A. C., \& Katz, L. F. (2013). Exploring the impact of parental psychopathology and emotion regulation on evidence-based parenting interventions: A transdiagnostic approach to improving treatment effectiveness. Clinical child and family psychology review, 16(2), 173-186. [Link]

Mazursky-Horowitz, H., Felton, J. W., MacPherson, L., Ehrlich, K. B., Cassidy, J., Lejuez, C. W., \& Chronis-Tuscano, A. (2015). Maternal emotion regulation mediates the association between adult attention-deficit/hyperactivity disorder symptoms and parenting. Journal of abnormal child psychology, 43(1), 121-131. [Link]

Maher, E. J., Marcynyszyn, L. A., Corwin, T. W., \& Hodnett, R. (2011). Dosage matters: The relationship between participation in the Nurturing Parenting Program for infants, toddlers, and preschoolers and subsequent child maltreatment. Children and Youth Services Review, 33(8), 14261434. [Link]

McCabe, K., Yeh, M., Lau, A., Argote, C. B., \& Liang, J. (2010). Parent-child interactions among lowincome Mexican American parents and preschoolers: do clinic-referred families differ from nonreferred families? Behavior Therapy, 41(1), 8292. [Link]

Mofrad, S., Abdullah, R., \& Samah, B. A. (2009). Perceived parental overprotection and separation anxiety: Does specific parental rearing serve as specific risk factor. Asian Social Science, 5(11), 109-116. [Link]

Myers, S. S., \& Pianta, R. C. (2008). Developmental commentary: Individual and contextual influences on student-teacher relationships and children's early problem behaviors. Journal of Clinical Child \& Adolescent Psychology, 37(3), 600-608. [Link]

Miller, P. H. (2002). Theories of developmental psychology. Macmillan. [Link]

Nesayan, A., Amani, M., \& Gandomani, R. A. (2019). Cognitive Profile of Children and its Relationship With Academic Performance. Basic and clinical neuroscience, 10(2), 165. [Link]

N'zi, A. M., Lucash, R. E., Clionsky, L. N., \& Eyber, S. M. (2017). Enhancing parent-child interaction therapy with motivational interviewing techniques. Cognitive and Behavioral Practice, 24(2), 131-141. [Link]

O'Connor, E., \& McCartney, K. (2006). Testing associations between young children's relationships with mothers and teachers. Journal of Educational Psychology, 98(1), 87. [Link]

Pempek, T. A., \& Lauricella, A. R. (2017). The effects of parent-child interaction and media use on cognitive development in infants, toddlers, and preschoolers. In Cognitive development in digital contexts (pp. 53-74). Academic Press. [Link]

Pajares, F., \& Schunk, D. (2001). The development of academic self-efficacy. Development of achievement motivation. United States, 7, 1-27. [Link]

Pourmohammadreza-Tajrishi M, A'shouri M, Afrouz G A, Arjmand-nia A A, Ghobari-Bonab B. (2015). The Effectiveness of Positive Parenting Program (Triple-P) Training on Interaction of Mother-child with Intellectual Disability. jrehab. 16 (2):128-137. [Link]

Rhoades, B. L., Greenberg, M. T., Lanza, S. T., \& Blair, C. (2011). Demographic and familial predictors of early executive function development: Contribution of a person-centered perspective. Journal of Experimental Child Psychology, 108(3), 638-662. [Link]

Roshan, M., Aghayousefi, A., Alipour, A., Rezaee, A. (2020). Effectiveness comparison of parent-child interaction therapy and mother's coping therapy on reduction of intensity of child behavior problems in 3-6 year old children. Clinical Psychology and Personality, 14(1), 111-123. [Link]

Reynolds, A. J., Temple, J. A., Robertson, D. L., \& Mann, E. A. (2001). Long-term effects of an early childhood intervention on educational achievement and juvenile arrest: A 15-year follow-up of lowincome children in public schools. Jama, 285(18), 2339-2346. [Link]

Stewart, S. M., \& Emslie, G. J. (2020). Extending ParentChild Interaction Therapy to Preschool Children Who Are Depressed. Journal of the American Academy of Child and Adolescent Psychiatry, 59(7), 803-804. [Link]

Sexton, T. L. (2019). Functional family therapy: An evidence-based, family-focused, and systemic approach for working with adolescents and their families. [Link]

Sanders, M. R. (2003). Triple P-Positive Parenting Program: A population approach to promoting competent parenting. Australian e-journal for the Advancement of Mental Health, 2(3), 127-143. [Link]

Sabanathan, S., Wills, B., \& Gladstone, M. (2015). Child development assessment tools in low-income and 
middle-income countries: how can we use them more appropriately? Archives of disease in childhood, 100(5), 482-488. [Link]

Schuman, S. L., Graef, D. M., Janicke, D. M., Gray, W. N., \& Hommel, K. A. (2013). An exploration of family problem-solving and affective involvement as moderators between disease severity and depressive symptoms in adolescents with inflammatory bowel disease. Journal of clinical psychology in medical settings, 20(4), 488-496. [Link]

Stephens, M. A. (2009). Gender differences in parenting styles and effects on the parent-child relationship. 1-26. [Link]

Silk, J. S., Shaw, D. S., Skuban, E. M., Oland, A. A., \& Kovacs, M. (2006). Emotion regulation strategies in offspring of childhood-onset depressed mothers. Journal of Child Psychology and Psychiatry, 47(1), 69-78. [Link]

Stright, A. D., Neitzel, C., Sears, K. G., \& Hoke-Sinex, L. (2001). Instruction begins in the home: Relations between parental instruction and children's selfregulation in the classroom. Journal of Educational Psychology, 93(3), 456. [Link]

Shafiee S, Hashemirazini H, Shahgholian M. (2018). The Role of Parent-Child Interaction and Sensory Processing Pattern in Predicting Children's Internalizing and Externalizing Problems. JOEC. 18 (1):19-32. [Link]

Satoorian, S. A., Tahmassian, K., Ahmadi, M. R. (2017). The Role of Parenting Dimensions and Child-Parent Relationship in Children's Internalized and Externalized Behavioral Problems. Family Research 12(4): 683-705. [Link]

Tamis-LeMonda, C. S., Bornstein, M. H., \& Baumwell, L. (2001). Maternal responsiveness and children's achievement of language milestones. Child development, 72(3), 748-767. [Link]

Talei, A., Tahmasian, K., vafai, N. (2011). Effectiveness of Positive Parenting Program Training on Mothers' Parental Self-Efficacy. Family Research. 7(3); 311323. [Link]

Tahmasbi A, khosropour F. (2019). The effectivness of parent-child relationship management (CPRT) on social skills and emotional regulation of children under the age of 12 with ADHD. Rooyesh. 8 (6): 113-122. [Link]

Trunzo, A. C. (2006). Engagement, parenting skills, and parent-child relations as mediators of the relationship between parental self-efficacy and treatment outcomes for children with conduct problems (Doctoral dissertation, University of Pittsburgh). Esther Sales, Faculty, School of Social Work. University of Pittsburgh.1-111. [Link]

UNICEF.(2018). Learning through play Strengthening learning through play in early childhood education programmes. Published by UNICEF Education Section, Programme Division 3 United Nations Plaza New York, NY 10017, USA. United Nations Children's Fund (UNICEF). [Link]

Vigil, D. C., \& Hwa-Froelich, D. A. (2004). Interaction styles in minority caregivers: Implications for intervention. Communication Disorders Quarterly, 25(3), 119-126. [Link]

Wallace, N. M., Quetsch, L. B., Robinson, C., McCoy, K., \& McNeil, C. B. (2018). Infusing parent-child interaction therapy principles into communitybased wraparound services: An evaluation of feasibility, child behavior problems, and staff sense of competence. Children and Youth Services Review, 88, 567-581. [Link]

Yoshizumi, T., Murase, S., Murakami, T., \& Takai, J. (2007). Dissociation as a mediator between perceived parental rearing style and depression in an adult community population using college students. Personality and Individual Differences, 43(2), 353364. [Link]

Zhang, X. (2011). Parent-child and teacher-child relationships in Chinese preschoolers: The moderating role of preschool experiences and the mediating role of social competence. Early Childhood Research Quarterly, 26(2), 192-20. [Link]

Zare, H, Tahmassiyan, K, Pakdaman, Sh, Davari Ardakani, N, Rahimi, T. (2016). Observing Iranian Mother-Child Interaction in a Playing Situation. Family Research 12(1):7-25. [Link]

Zabihi jalali zavareh E, Kazemian S, kasaee A. (2020). Factors influencing of pre-school and elementary school periods on field selection of educational for ninth grade students: qualitative research. Journal of Psychological Science. 9(89)561-566. [Link]

Zare Bahramabadi, M., Zahrakar, K., Salehian Broojerdi, H., Mohammadifar, M. (2013). The Effectiveness of Relationship Enhancement Program on Quality of Parent-Child Relationship in Mothers who are Heads of Household in Single-Parent Families. Journal of Clinical Psychology, 5(2), 14-24. [Link] 